\title{
Jörg Bölling
}

\section{Zwischen kirchlicher Liturgie und korporativer Frömmigkeitspraxis Motetten am Papsthof der Renaissance}

De ultimo symphonizantium choro nihil ad nostras caerimonias pertinet, qualiter ipsi stare aut sedere vel aliquid facere, quod eis libeat aut liceat. ${ }^{1}$

So äußert sich bekanntlich Paris de Grassis, oberster päpstlicher Zeremoniar des frühen 16. Jahrhunderts. Chordienst und Chormusik, Gottesdienst und Gesang scheinen demnach um 1500 wenig miteinander zu tun gehabt zu haben - so jedenfalls ist diese Passage in einschlägigen Forschungsbeiträgen verstanden worden. ${ }^{2}$ Dem magister caerimoniarum geht es aber an dieser Stelle um etwas anderes: um die Frage von Sessionsordnung und Körperhaltung in der Sixtinischen Kapelle. ${ }^{3}$ Bei Prozessionen haben sich die Sänger als eigene Korporation an die geltende Ordnung zu halten - zeitlich und räumlich. ${ }^{4}$ In der Sixtinischen Kapelle hingegen waren die »cantores « solchen Rang- und Präzedenzfragen buchstäblich »enthoben«, indem sie von ihrer Sängerkanzel aus über das zeremonielle Treiben, gerade auch über die von Paris als wenig gottesdienstlich gerügten Ränkeleien, im doppelten Sinne hinwegsehen konnten. Nur zu bestimmten liturgischen Anlässen, etwa im österlichen Triduum, verließen einzelne von ihnen die Sängerkanzel und

1 »Beim letzten Chor, dem der Sänger, betrifft nichts unsere Zeremonien - auf welche Weise die Sänger stehen oder sitzen oder auch etwas anderes machen, das ihnen beliebt oder erlaubt ist.« Paris de Grassis, Caerimoniarum opusculum, I-Rvat Vat. lat. 5634 I, Fol. $28^{\mathrm{r}}$ und I-R Archivio Segreto Vaticano, Fondo Borghese, serie I, 568, fol. $34^{\mathrm{v}}$.

2 Auf eine »ausgeprägte Arbeitsteilung « verweist zu Recht bereits Rafael Köhler, »Pervia Coelos. Formen päpstlicher Huldigung in der polyphonen Meßvertonung des 16. Jahrhunderts«, in: Collectanea II. Studien zur Geschichte der päpstlichen Kapelle. Tagungsbericht Heidelberg 1989, hrsg. von Bernhard Janz, Vatikanstadt 1994 (Capellae Apostolicae Sixtinaeque Collectanea Acta Monumenta, 4), S. 351-404, S. 353 mit Anm. 7 - ein Befund, der die Frage nach wechselseitigen Bezügen zwischen Zeremonial- und Musikentwicklung jedoch nicht beantwortet, sondern neu aufwirft.

3 Diesem Aspekt ist das gesamte Kapitel des Traktates, aus dem das Zitat stammt, gewidmet. Vgl. Jörg Bölling, Das Papstzeremoniell der Renaissance. Texte - Musik - Performanz, Frankfurt am Main 2006 (Tradition - Reform - Innovation, 12), S. 64-68 (zum Traktat) und S. 113119 (zum Kapitel De ordine sedendi ac manendi in Cappella Papali und seinen intertextuellen Bezügen).

4 Ebda., S. 129-134. 


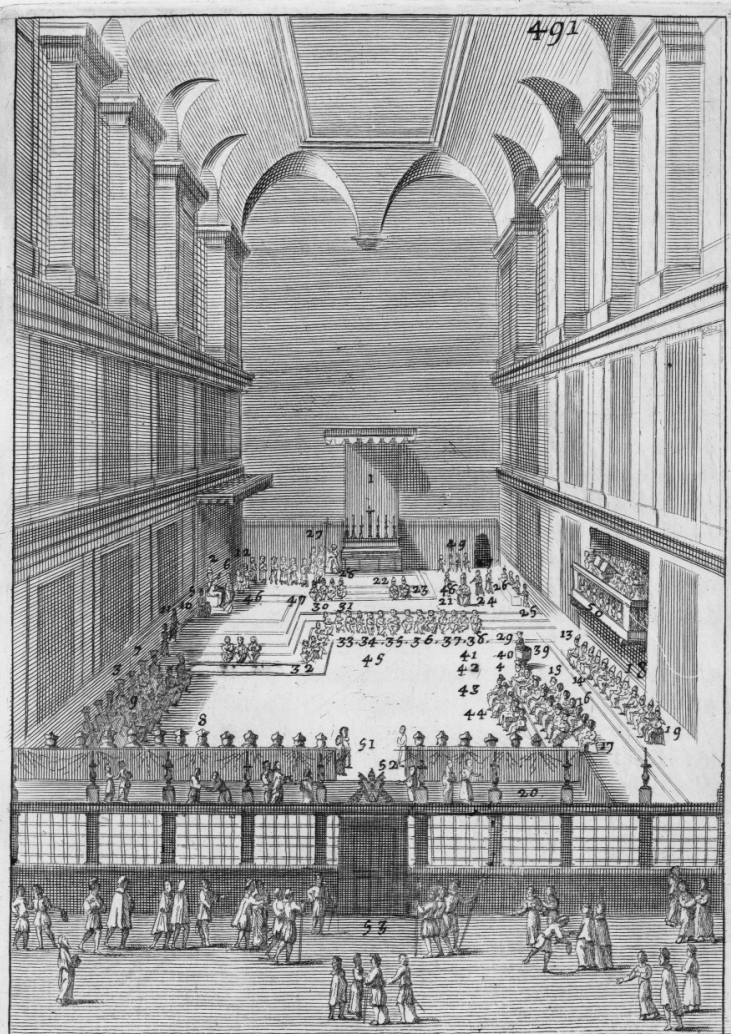

Disegno della Cappella Pontificia publicato nel Pontificato di Sisto $V$.
Abbildung 1: Filippo Bonanni, La Gerarchia Ecclesiastica ..., Rom 1720, Abb. Nr. 157 (bei S. 491). Die Sängerkanzel ist mit der Nr. 50 bezeichnet (Foto: Bildarchiv, SUB Göttingen)

durchschritten die Kapelle, um unmittelbar vor dem Altarraum eine Lesung vorzutragen. Gleich danach gingen aber auch diese als liturgischer Kantor im engeren Sinne fungierenden »cantores« auf ihre Sängerkanzel zurück (vgl. Abbildung 1$).^{5}$

5 Ebda., S. 134-148. Der in Abbildung 1 gezeigte Stich aus Filippo Bonanni, La Gerarchia Ecclesiastica ..., Rom 1720, Abb. 157 (bei S. 491) geht, wie bereits der Untertitel verdeutlicht, auf eine Vorlage von Étienne Dupérac zurück. Kurz vor Bonanni hat auch der damalige Kapellmeister der Sixtinischen Kapelle, Andrea Adami, diesen Stich von Filippo Iuvara nachzeichnen und stechen lassen. Siehe dazu Andrea Adami, Osservazioni per ben regolare il coro de $i$ cantori della Cappella Pontificia, tanto nelle funzioni ordinarie, che straordinarie, Rom 1711, mit einer 
Auf dieser ihrer Sängerkanzel galten ihre eigenen Gesetze, die allein der $\mathrm{Mu}-$ sik und ihrer Korporation dienten. Innerhalb dieses ihres Sängerortes blieben die bedeutendsten Musiker und Komponisten sogar über ihr zeitlich begrenztes Wirken hinaus dauerhaft präsent - in Form von Graffiti, auf die ihre Nachfolger ihrerseits Bezug nahmen. ${ }^{6}$

Anders als mit dem Raum verhielt es sich mit der Zeit. ${ }^{7}$ Paris de Grassis gibt darüber Auskunft, und zwar in bis dahin unbekannter Ausführlichkeit und Detailtreue eines erfahrenen Experten. Seine Aussagen lassen sich besonders für die Messensätze nutzen: für eine Rekonstruktion des Ineinanders der vier verschiedenen so genannten $»$ Chöre $\aleph^{8}$ mit ihren jeweiligen Korporationen. Chöre im Sinne des Zeremonienmeisters sind erstens der Papst mit seiner Thronassistenz, stadtadligen Korporationsvertretern und diplomatischem Corps, zweitens die geistlichen Chordiener und Leviten des Altares, drittens der dreifach hierarchisch gestufte Chor der Kardinalbischöfe, Kardinaldiakone und Kardinalpriester und schließlich viertens der einzige professionell singende Chor: die »cantores $«{ }^{9}$ Diese vier Gruppen verrichteten

Einführung, Bibliographie und Index neu hrsg. von Giancarlo Rostirolla, Lucca 1988 (Musurgiana, 1), vor S. 1. Zu den unterschiedlichen Kopien siehe auch Niels Krogh Rasmussen, »Maiestas Pontificia. A Liturgical Reading of Étienne Dupérac's Engraving of the Capella Sixtina from 1578«, in: Analecta Romana Instituti Danici 12 (1983), S. 109-148: S. 109-113.

6 Klaus Pietschmann, »Die Sängergraffiti auf der Cantoria der Sixtinischen Kapelle zwischen Selbstglorifizierung und memorialer Frömmigkeit«, in: Musik in Rom im 17. und 18. Jabrhundert. Kirche und Fest. Tagungsbericht Rom, Oktober 1999, hrsg. von Markus Engelhardt und Christoph Flamm, Laaber 2004 (Analecta Musicologica, 33), S. 81-94; ders., Kirchenmusik zwischen Tradition und Reform. Die päpstliche Kapelle und ibr Repertoire im Pontifikat Pauls III. (1534-1549), Vatikanstadt 2007 (Capellae Apostolicae Sixtinaeque Collectanea Acta Monumenta, 11), S. 318-321; ders. »Die Graffiti auf der Sängerkanzel der Cappella Sistina. Vollständiger Katalog und Dokumentation«, in: Institutionalisierung als Prozess. Organisationsformen musikalischer Eliten im 15. und 16. Jahrhundert, Kongressbericht Rom, Dezember 2005, hrsg. von Birgit Lodes und Laurenz Lütteken, Laaber 2009 (Analecta Musicologica, 43), S. 225-273.

7 Jörg Bölling, »Zeremoniell und Zeit. Messkult und Musikkultur am Papsthof der Renaissance«, in: Polyphone Messen im 15. und 16. Jahrhundert. Funktion, Kontext, Symbol. Tagung des SFB 496 in Münster, hrsg. von Andrea Ammendola, Daniel Glowotz und Jürgen Heidrich, Göttingen 2012, S. 145-186.

8 Zu Herkunft und Verwendung des Begriffs »chorus« am Papsthof der Renaissance siehe ebda., S. 151-153; zur älteren Tradition siehe Josef Andreas Jungmann, Missarum Sollemnia. Eine genetische Erklärung der römischen Messe, 2 Bde., Wien u. a. ${ }^{5} 1962$ (Repr. Bonn 2003), Bd. 1, S. 164f. und neuerdings Marius Linnenborn, Der Gesang der Kinder in der Liturgie. Eine liturgiewissenschaftliche Untersuchung zur Geschichte des Chorgesangs, Regensburg 2012 (Studien zur Pastoralliturgie, 26), S. 106f.

9 J. Bölling, Das Papstzeremoniell der Renaissance (wie Anm. 3), S. 113-128; ders., Zeremoniell und Zeit (wie Anm. 7), S. 150-173. 
ihre Gebete getrennt und unabhängig voneinander, kamen nur an bestimmten Stellen zusammen. ${ }^{10}$ Darüber hinaus gab es eine Reihe weiterer korporativ verfasster Amtsträger, für die ihrem Rang in den Kapellgottesdiensten entsprechend nicht nur räumlich-architektonische, sondern auch zeitlichmusikalische Regeln galten. Da es sich mit Ausnahme der professionellen »cantores« um für den gegebenen Zusammenhang wenig interessante Formen von Gesängen und Akklamationen handelte, seien diese hier nicht näher ausgeführt. ${ }^{11}$

Wesentlich weniger deutlich als die zeremonialen Angaben zur Messe sind allerdings diejenigen zu Motetten. Warum werden von den Zeremoniaren wie Paris de Grassis und seinem Vorgänger Johannes Burckard einige genannt, darunter notenmäßig nicht überlieferte, andere wiederum unerwähnt gelassen, darunter auf uns gekommene musikalische Meisterwerke? Neben der offiziellen, stets im Mittelpunkt der Betrachtung stehenden Liturgie scheint es Frömmigkeitskonzepte gegeben zu haben, die sich mit rein zeremonialen Quellen nur zu einem gewissen Teil oder auf Umwegen erschließen lassen. Da das Sängerkollegium eine eigenständige Korporation innerhalb der »cappella papalis« darstellte, pflegte es eigene Formen religiöser Praxis. Die Aufführung von Motetten bot die Möglichkeit, neben den amtlich liturgischen Texten der gesamten Kirche auch Frömmigkeitsformen der eigenen Korporation in das mediale Spektrum päpstlicher Repräsentation um 1500 einzubringen. Hierunter fallen jene »Sängergebete « ${ }^{12}$, die sich das Kollegium als Ganzes zu eigen machte, aber auch Texte und deren Vertonungen, die bestimmte Auftraggeber von außen vorgaben.

Die konkrete Aufführungspraxis der Motetten lässt sich aber leider nur in Teilen und sehr bedingt rekonstruieren, da die überlieferten Motetten in den offiziellen Tagebüchern der Zeremonienmeister bis auf wenige Ausnahmen nicht erwähnt werden. ${ }^{13}$ Die Verschriftlichung verlief bei den Zeremoniaren und Musikern etwa zeitgleich und in funktionaler Analogie. Interdependenzen ergaben sich jedoch nicht zwischen literarischem Text und musikalischer

10 Vgl. dazu J. Bölling, Das Papstzeremoniell der Renaissance (wie Anm. 3), S. 125-127; ders., Zeremoniell und Zeit (wie Anm. 7).

11 Siehe dazu J. Bölling, Das Papstzeremoniell der Renaissance (wie Anm. 3), S. 149-195.

12 Siehe dazu Rafael Köhler, Die Cappella Sistina unter den Medici-Päpsten 1513-1534. Musikpflege und Repertoire am päpstlichen Hof, Kiel 2001, S. 162.

13 Siehe dazu die anderen Beiträge dieses Bandes sowie die weiteren umfänglichen musikgeschichtlichen Studien von Adalbert Roth, Richard Sherr, Raffael Köhler und Klaus Pietschmann. 
Komposition, sondern allein auf der Ebene der Performanz. ${ }^{14}$

Gerade deshalb aber bieten sich Motetten als besonderer Untersuchungsgegenstand an: Standen sie gattungsspezifisch nach Johannes Tinctoris als »cantus mediocris« zwischen dem »cantus magnus « der Messe und dem »cantus parvus« der Kantilene, so spiegelten sie in Text und Faktur weltliche wie geistliche Aspekte wider und nahmen dadurch im spannungsreichen Verhältnis von kirchlicher Liturgie und korporativer Frömmigkeitspraxis der päpstlichen Kapelle und anderer am Papsthof wirkender Sänger eine vermittelnde Rolle ein. Im Folgenden sei daher der Frage nachgegangen, inwieweit Motteten aufgrund der besonderen Institutionalität ihrer jeweiligen Korporation (I.) und der Verschriftlichung, Gebrauchsfunktion und Verwahrung ihrer Kompositionen (II.) eine besondere Performanz von Korporationen und Kompositionen (III.) erkennen lassen.

\section{Die Institutionalität der Korporationen}

Am Papsthof waren zu bestimmten Anlässen verschiedene Sänger zu hören. Den ersten Platz nahmen selbstredend die Sänger des Papstes selbst ein: seine »cappella papalis«. Der Begriff »cappella« wurde schon im frühen 15. oft weniger mit der im 11. Jahrhundert nach kaiserlichem Vorbild errichteten päpstlichen Hofkapelle in Verbindung gebracht, als vielmehr mit den Sängern der Kurie. ${ }^{15}$ Während des Pontifikats Clemens' VII. (1523-1534) etablierte sich dieser Begriff als spezielle Bezeichnung des Sängerkollegs. ${ }^{16}$ Die Anfänge dieses singenden Personenverbandes liegen in Avignon. Um die Aufgabenbereiche Liturgie und Verwaltung zu trennen, gründete Benedikt XII. (1334-1342) aus dem Personenkreis seiner Kapelle die Korporation der »capellani capellae papae«, die man später »capella intrinseca« oder

14 J. Bölling, Das Papstzeremoniell der Renaissance (wie Anm. 3), S. 21-78 (zu den Zeremonialschriften) und S. 196-270 (zum performativen Verhältnis von ausgeführten Zeremonien und erklingendem musikalischem Repertoire). Zum hier vor allem im sprachwissenschaftlichen Sinne benutzten Begriff der »Performanz« sowie zu dessen Verwendung in den Theaterwissenschaften und in der Geschlechterforschung siehe ebda. S. 12f. mit Anm. 9.

15 Vgl. Sabine Ehrmann-Herfort, »Cappella / Kapelle«, in: Handwörterbuch der musikalischen Terminologie, nach Hans Heinrch Eggebrecht, hrsg. von Albrecht Riethmüller, 35. Auslieferung, Sommer 2003, S. 6; J. Bölling, Das Papstzeremoniell der Renaissance (wie Anm. 3), S. 15-20 und ders., »Die zwei Körper des Apostelfürsten. Der heilige Petrus im Rom des Reformpapsttums«, in: Römische Quartalschrift für christliche Altertumskunde und Kirchengeschichte 106 (2011), S. 215-252: S. 232-234.

16 Siehe dazu R. Köhler, Die Cappella Sistina (wie Anm. 12), S. 15 mit Anm. 32. 
»capella secreta« nannte. Verwaltungstechnische Aufgaben, also das Geschäft der klassischen kurialen Kapelle und Kanzlei, übernahmen fortan die »capellani commensales«, wohingegen die neu gegründete »capella secreta« sich auf die musikalische Ausgestaltung von Stundengebet und Messe konzentrieren konnte. ${ }^{17}$ Nach leichten strukturellen Veränderungen durch Martin V. ${ }^{18}$ und Eugen IV. ${ }^{19}$ fand die Entwicklung dieser Institution gegen die Mitte des 15. Jahrhunderts ihren vorläufigen Abschluss: Nun bestand die »cappella papalis« aus »sacrista «, »magister capellae «, »clerici« und »magistri cerimoniarum «, $»$ capellani missarum «, $\gg$ cantores $«$ und $»$ campanarii ${ }^{20}{ }^{20}$

Durch die gezielte Anwerbung neuer Sänger wurde bald die regelmäßige Aufführung anspruchsvoller polyphoner Werke möglich, ${ }^{21}$ vor allem von Messen und Motetten. Von einer gefestigten Institutionalität des Sängerkollegiums zeugen auch die Statuten und deren fragmentarisch überlieferte Vorläufer. $^{22}$

Drei Aspekte kennzeichnen die Sänger als eigenständige Korporation:

17 Vgl. Andrew Tomasello, Music and Ritual at Papal Avignon 1309-1403, Ann Arbor 1983, S. 151f.; Laurenz Lütteken, Guillaume Dufay und die isorhythmische Motette. Gattungstradition und Werkcharakter an der Schwelle zur Neuzeit, Hamburg und Eisenach 1993 (Schriften zur Musikwissenschaft aus Münster, 4), S. 225.

18 Manfred Schuler, »Zur Geschichte der Kapelle Papst Martins V.«, in: Archiv für Musikwissenschaft 25 (1968), S. 30-45.

19 Manfred Schuler, »Zur Geschichte der Kapelle Papst Eugens IV.«, in: Acta musicologica 40 (1968), S. 220-227, und L. Lütteken, Guillaume Dufay und die isorhythmische Motette (wie Anm. 17), S. 226-231.

20 Bernhard Schimmelpfennig, Die Zeremonienbücher der römischen Kurie im Mittelalter, Tübingen 1973 (Bibliothek des deutschen Historischen Instituts in Rom, 10), S. 80f.; ders., »Die Funktion der Cappella Sistina im Zeremoniell der Renaissancepäpste«, in: Collectanea II (wie Anm. 2), S. 123-174: S. 143-146; L. Lütteken, Guillaume Dufay und die isorhythmische Motette (wie Anm. 17), S. 226, Anm. 55; K. Pietschmann, Kirchenmusik zwischen Tradition und Reform (wie Anm. 6), S. 109-176 sowie S. 400-408. Die Leitung oblag dem »magister capellae«. Pamela F. Starr, »Towards the Cappella Sistina: A profile of the Cappella Pontificia during the Pontificates of Nicholas V, Calixtus III, Pius II, and Paul II (1447-1471)«, in: Collectanea II (wie Anm. 2), S. 451-475: S. 454 mit Anm. 13, hinterfragt von Richard Sherr (ebda. S. 468f.), geht davon aus, dass im 15. Jahrhundert zwischenzeitlich der stets an erster Stelle genannte, sonst eher für Fragen der Kleidung zuständige »sacrista« die Leitung auch der Sänger inne hatte.

21 Vgl. Adalbert Roth, »Liturgical (and Paraliturgical) Polyphonic Music in the Papal Chapel towards the End of the Fifteenth Century. A Repertory in Embryo«, in: Music, Musicians and Musical Culture in Renaissance Rome, hrsg. von Richard Sherr, Oxford u.a. 1998, S. 125-137 (Lit.); K. Pietschmann, Kirchenmusik zwischen Tradition und Reform (wie Anm. 6), S. 55-72.

22 R. Köhler, Die Cappella Sistina (wie Anm. 12), S. 19-29 und die Editionen S. 217-243; K. Pietschmann, Kirchenmusik zwischen Tradition und Reform (wie Anm. 6), S. 115-123. 
1. die Begriffe »cappella«, »collegium cantorum«, »capitulum« und $»$ congretatio«,

2. die Verpflichtung der Sänger zum regelmäßigen Gottesdienst (Stundengebet und Messe),

3. die Verfahren bei Neuaufnahmen und Wahl des so genannten Abtes. ${ }^{23}$

Innerhalb der Kapelle sind ihrer Herkunft nach verschiedene Gruppierungen zu unterscheiden, für die meist - wie bei Konzilien - der Begriff »nationes« gebraucht wird. Waren fast alle Sänger der Avignonesischen Gegenpäpste fast ausschließlich Franzosen gewesen, ${ }^{24}$ so traten im Rahmen der Erneuerung der Kapelle unter den Renaissancepäpsten auch Italiener und Spanier hinzu, ${ }^{25}$ ferner Engländer und »Deutsche«, insbesondere aus den heutigen Beneluxstaaten. ${ }^{26}$ Musikalisch äußerte sich dies mitunter in unterschiedlichen, regelrechten Nationalstilen. ${ }^{27}$

Doch für die päpstlichen Kapellsänger, gleich welcher Provenienz, bildete nicht nur die Sängerkapelle selbst eine tragende Institution: Bereits für die Jahre 1483 und 1484 ist belegt, dass die meisten Kapellsänger Mitglieder der Confraternità di Santo Spirito in Sassia waren. ${ }^{28}$ Klaus Pietschmann hat darüber hinaus Sänger ausfindig gemacht, die weiteren Bruderschaften

23 Vgl. dazu ausführlich R. Köhler, Die Cappella Sistina (wie Anm. 12), S. 31-48.

24 Vgl. Adalbert Roth, »Zur >Reform (1471-1484)«, in: Zusammenhänge, Einflüsse, Wirkungen. Kongreßakten zum ersten Symposium des Mediävistenverbandes in Tübingen 1984, hrsg. von Joerg O. Fichte, Karl Heinz Göller und Bernhard Schimmelpfennig, Berlin und New York 1986, S. 168-195: S. 176 mit Anm. 24f.

25 Vgl. ebda., S. 177-192 (Übersicht über die Zusammensetzung des Sängerkollegiums unter Martin V. bis Sixtus IV.) sowie P. Starr, Towards the Cappella Sistina (wie Anm. 20), pass. (Nikolaus V. bis Paul II.); Richard Sherr, The Papal Chapel ca. 1492-1513 and its Polyphonic Sources, Diss. Princeton 1975, S. 47-77 und S. 263-272 (Alexander VI. bis Julius II.) und R. Köhler, Die Cappella Sistina (wie Anm. 12), S. 74-87 (Leo X. bis Clemens VII.).

26 Sämtliche Kapellsänger, die in den Mitgliederlisten der deutschen Bruderschaften Roms geführt werden, kamen aus diesem grenzübergreifenden, für die Musik- und Kunstgeschichte in Nord und Süd so bedeutenden Gebiet zwischen Frankreich und dem Reich. Siehe dazu und zu den zahlenmäßig noch bedeutenderen deutschen Lautenmachern in Rom Klaus Pietschmann, »Deutsche Musiker und Lautenmacher im Rom der Renaissance. Spuren im Campo Santo Teutonico und der deutschen Nationalkirche Santa Maria dell'Anima«, in: Deutsche Handwerker, Künstler und Gelehrte im Rom der Renaissance, hrsg. von Stephan Füssel und Klaus A. Vogel, Wiesbaden 2000 (Pirckheimer Jahrbuch für Renaissance- und Humanismusforschung, 15), S. 181-213.

27 Vgl. J. Bölling, Das Papstzeremoniell der Renaissance (wie Anm. 3), S. 153-157 (Quellen und Lit.).

28 Vgl. R. Sherr, The Papal Chapel (wie Anm. 25), S. 48 mit Anm. I (Biblioteca Lancisiana, Codex 328, fol. 93- $-94^{\mathrm{r}}$ ). 
angehörten, unter anderem jenen der Kirche Santa Maria dell'Anima und des Campo Santo Teutonico. ${ }^{29}$

Neben dem »collegium« der »cantores cappellae papae« waren auch weitere Sängerkorporationen im Kapellgottesdienst und wohl auch im päpstlichen Palast zu hören, die imstande waren, Motetten aufzuführen. Doch sofern es sich nicht um Privatgottesdienste auswärtiger Gäste ohne Beteiligung des päpstlichen Hofes handelte, ${ }^{30}$ hatten sich diese allesamt an die Liturgie der päpstlichen Kapelle zu halten. Nicht einmal den Dominikanern, die einen eigenen Ritus pflegten, wollten die päpstlichen Zeremoniare Sonderriten zugestehen. ${ }^{31}$ Das Konzil von Trient und die neu geschaffene Ritenkongregation der Kurie ließen sämtlichen Dominikanern ihre liturgischen Eigenheiten. ${ }^{32}$ Paris de Grassis hingegen betrachtete sich noch höchst selbst als »censor caerimoniarum «, dem die entscheidende »censura « oblag. ${ }^{33}$ Unverrückbares Vorbild aller Zeremoniare der Renaissance blieb zeit- und raumübergreifend die »cappella papalis« - als architektonischer Gottesdienstraum, liturgische Gottesdienstform und den Gottesdienst feiernder Personenverband, einschließlich des »collegium cantorum $\ll .{ }^{34}$

29 K. Pietschmann, Deutsche Musiker und Lautenmacher im Rom der Renaissance (wie Anm. 26). Zur Mitgliedschaft in weiteren Bruderschaften siehe ders., Kirchenmusik zwischen Tradition und Reform (wie Anm. 6), S. 337-342.

30 Vgl. etwa die Beispiele bei Sabine Žak, »Cappella - castello - camera. Gesang und Instrumentalmusik an der Kurie«, in: Collectanea II. (wie Anm. 2), S. 175-223: S. 195f. und 21 lf.

31 Paris de Grassis etwa mochte gleich zu Beginn seiner Amtszeit im Frühjahr 1504 seinem Tagebucheintrag nach selbst bei den so einflussreichen Dominikanern von Santa Maria sopra Minerva keine Ausnahme machen. I-Rvat, Vat. lat. 12272, fol. $5^{\mathrm{v}}$ (gestempelt $4^{\mathrm{v}}$ ): »Postea sederunt et fratres de Minerva simili modo ... et cantarunt laudes sub Antifonis simplicibus, de qua re cum ipsos redarguerem, responderunt sese non facere officium secundum Morem Romanae Curie.«

32 Riten von Orden oder Diözesen, die älter als 200 Jahre waren, blieben von den liturgischen Reformen des Konzils von Trient unangetastet. Den monastischen Gemeinschaften wurde lediglich der Verzicht auf mehrstimmige Musik nahegelegt. Vgl. Jörg Bölling, »Zur Erneuerung der Liturgie in Kurie und Kirche durch das Konzil von Trient (1545-1563). Konzeption Diskussion - Realisation«, in: Papsttum und Kirchenmusik vom Mittelalter bis zu Benedikt XVI.: Positionen - Entwicklungen - Kontexte, hrsg. von Klaus Pietschmann (Analecta musicologica, 47), Kassel u.a. 2012, S. 124-145: S. 140 und S. 143 mit Anm. 92.

33 Vgl. I-Rvat Vat. lat. 4739, fol. $\mathrm{I}^{\mathrm{r}}{ }^{N}$. S. dazu ausführlich Bölling, Das Papstzeremoniell der Renaissance (wie Anm. 3), S. 109-112.

34 Vgl. J. Bölling, Das Papstzeremoniell der Renaissance (wie Anm. 3), S. 113-128. Speziell zu Paris de Grassis siehe ders., »Das Papstzeremoniell der Hochrenaissance. Normierungen Modifikationen - Revisionen«, in: Ekklesiologische Alternativen? Monarchischer Papat und Formen kollegialer Kirchenleitung (15.-20. Jahrbundert), hrsg. von Bernward Schmidt und Hubert Wolf, Münster 2013, S. 273-307: S. 271-293. 


\section{Die Schriftlichkeit der Kompositionen}

Anders als die Institution von Kapelle und Kollegium der Sänger erfuhr die Komposition, Aufführung und Verschriftlichung am Avignonesischen Papsthof keine Förderung, sondern sogar eine Beschränkung. In seiner 1324/25 promulgierten Bulle »Docta sanctorum patrum « kritisierte Papst Johannes XXII. (1316-1334) die Musikpraxis weltlicher Hofkapellen wie die des französischen Hofes und begrenzte damit die Aufführung musikalisch anspruchsvoller Motetten ${ }^{35}$ - eine Entscheidung, die möglicherweise indirekt den Aufstieg der zyklischen Messkomposition förderte. ${ }^{36}$

Die Motettenüberlieferung im Fondo Cappella Sistina wird von Thomas Schmidt-Beste dargestellt. ${ }^{37}$ Auch außervatikanische Quellen sind bereits mit Blick auf mögliche Motetten des Papsthofes gesichtet worden. ${ }^{38}$ An dieser Stelle soll das Augenmerk hingegen exemplarisch einer Motette gewidmet sein, deren Text und Aufführungszusammenhang hinlänglich bekannt, doch kaum näher untersucht worden ist: Gaude Roma vetus. ${ }^{39}$

35 A. Tomasello, Music and Ritual at Papal Avignon 1309-1403 (wie Anm. 17), S. 107-122. Zur Ablehnung von Motetten und Kantilenen durch die Bulle siehe Helmut Hucke, »Das Dekret >Docta sanctorum patrum< Papst Johannes' XXII.«, in: Musica Disciplina 38 (1984), S. 119131: S. 125 mit Anm. 32; siehe neuerdings auch Franz Körndle, »Die Bulle Docta sanctorum patrum. Überlieferung, Textgestalt und Wirkung «, in: Die Musikforschung 63 (2010), S. 147-165.

36 Ludwig Finscher, »Die Messe als musikalisches Kunstwerk«, in: Nenes Handbuch der Musikwissenschaft, hrsg. von Carl Dahlhaus, fortgefuihrt von Hermann Danuser, Bd. 3, Darmstadt 1997, Teil 1, S. 193-276 und 295.

37 Vgl. den Beitrag von Thomas Schmidt-Beste in diesem Band.

38 Vgl. etwa die einschlägigen Veröffentlichungen von Joshua Rifkin.

39 Vgl. dazu bereits Johannis Burckardi Liber Notarum, 2 Bde., hrsg. von Enrico Celani Città di Castello 1906-1942 (Muratori, Rerum Italicarum Scriptores. Nuova Edizione 32, 1), Bd. 1, S. 376. Siehe dazu erstmals Arnold Schering, $»$ Musikalisches aus Joh. Burckards Liber notarum (1483-1506)«, in: Festschrift für Johannes Wolf zu seinem sechzigsten Geburtstage, hrsg. von Walter Lot, Helmuth Osthoff und Werner Wolffheim, Berlin 1929 (Nachdruck Hildesheim 1978), S. 171-175: S. 174f., und zuletzt Klaus Pietschmann, »Politisierte Vokalpolyphonie am Hof Maximilians I. im Kontext von Diplomatie und Zeremoniell. Heinrich Isaacs Optime pastor«, in: Die Habsburger und die Niederlande. Musik und Politik um 1500. Tagungsbericht, Münster 2009, hrsg. von Jürgen Heidrich (Troja Jabrbuch für Renaissancemusik 8 [2008/09]), S. 129142: S. 129 mit Anm. 2 (Lit.); ferner Jesse Rodin, Josquin's Rome. Hearing and Composing in the Sistine Chapel, Oxford 2012, S. 103. Thuasne ging in seiner Edition allerdings statt von Johannes Tinctoris auch noch von einem gewissen Johannes Cantor aus; vgl. Johannis Burchardi Diarium sive rerum urbanarum commentarii (1483-1506), 3 Bde., hrsg. von Louis Thuasne, Paris 1883-1885, Bd. 2, 1885, S. 13f. Dem im Vergleich zu Celani oft weniger zuverlässigen Thuasne ist an dieser Stelle zumindest in einem Punkt der Vorzug zu geben: Es muss grammatisch und metrisch korrekt »Claris cesaribus« heißen, nicht - wie Celani wohl rein versehentlich druckt - »Claribus cesaribus« (vgl. den Fließtext nach Anm. 59). 
Der Zeremonienmeister Johannes Burckard berichtet in seinem Tagebuch, die Sänger hätten am Zweiten Adventssonntag, dem 8. Dezember des Jahres 1492, auf Initiative des Vizekanzlers eine neu komponierte Motette "post offertorium « singen wollen, ${ }^{40}$ das heißt unmittelbar nach dem gregorianischen Gesang zur Bereitung und Darbringung der eucharistischen Gaben, wie es für Motetten üblich war. ${ }^{41}$ Der Papst habe diese Huldigung jedoch nicht entgegennehmen wollen - aus zwei Gründen: Zeit und Ort erschienen ihm unangebracht: $»$ noluit pro ea die, sed pro alia et in camera sua «. ${ }^{42}$ Die Zeitangabe eines anderen gewünschten Tages lässt zwei verschiedene Deutungen zu, eine liturgisch-amtliche und eine musikalisch-persönliche. Möglicherweise handelte es sich um eine Reverenz gegenüber der geprägten Zeit der Buße, wie sie traditionell geboten war. ${ }^{43}$ Ebenso denkbar ist aber auch, dass der erst wenige Monate amtierende Papst an diesem Tag nicht so viel Zeit verlieren oder umgekehrt dem im Kapellraum wohl kaum wahrnehmbaren Text einen akustisch passenderen Rahmen bieten wollte. Entsprechendes gilt für die Wahl des Ortes. Entweder wollte der Papst in seiner Kapelle ausschließlich liturgische Gesänge zulassen, ${ }^{44}$ oder aber er hörte Motetten generell lieber in seinen Gemächern, wie es zumindest für spätere Pontifikate nachweisbar ist. ${ }^{45}$ Dagegen spricht wiederum, dass der Papst seinem Vizekanzler wohl kaum die Bitte abgeschlagen hätte, ihm zu gratulie-

40 Johannis Burckardi Liber Notarum, hrsg. von Celani (wie Anm. 39), Bd. 1, S. 376, Z. 8-12: »Cantores capelle nostre per cardinalem vicecancellarium instigati voluerunt quandam laudem in pontificis honorem noviter compositam post offertorium decantasse; habita tamen super hoc per socium meum pontificis voluntate, qui id fieri noluit pro ea die, sed pro alia et in camera sua acceptavit, illam non cantarunt; erat autem laus hujusmodi, sub his verbis: ...«

41 Vgl. J. Bölling, Das Papstzeremoniell der Renaissance (wie Anm. 3), S. 238. Zum Begriff der Darbringung statt »Gabenbereitung « oder »Opferung« siehe unten Anm. 137.

42 Siehe oben Anm. 40.

43 Vgl. etwa Jörg Bölling, »Musicae utilitas. Zur Bedeutung der Musik im Adventus-Zeremoniell der Vormoderne «, in: Adventus. Studien zum herrscherlichen Einzug in die Stadt, hrsg. von Peter Johanek und Angelika Lampen, Köln u.a. 2009 (Städteforschung. Veröffentlichungen des Instituts für vergleichende Städtegeschichte in Münster. Reihe A: Darstellungen, 75), S. 229266: S. 246f. - Bonnie Blackburn zieht in einer mündlichen Äußerung - unabhängig von der erwähnten kirchenzeitlichen Angabe - sogar in Betracht, dass eine solche Motette in liturgischen Gottesdiensten grundsätzlich als unpassend betrachtet worden sei; vgl. Rodin, Josquin's Rome (wie Anm. 39), S. 103, Anm. 20.

$44 \mathrm{Vgl}$. Sabine Žak, »Fürstliche und städtische Repräsentation in der Kirche. Zur Verwendung von Instrumenten im Gottesdienst«, in: Musica disciplina 38 (1984), S. 231-259 und vor allem dies., Cappella - castello - camera (wie Anm. 30), S. 203-205.

$45 \mathrm{Vgl}$. Anthony M. Cummings, »Toward an Interpretation of the Sixteenth-Century Motet«, in: Journal of the American Musicological Society 24 (1981), S. 43-59: S. 45-48. 
ren, wenn er dabei nicht auch triftige inhaltliche Beweggründe vor Augen gehabt hätte. Es handelte sich dabei nämlich um Ascanio Maria Sforza (1455-1505), der seinem Vorgänger im Amt des Vizekanzlers, Rodrigo Borgia, durch Stimmenkauf zur Wahl als Papst Alexander VI. verholfen hatte, um seinerseits daraus Nutzen zu ziehen. ${ }^{46}$ Der neu gewählte Papst ging dann jedoch eigene Wege. Daher mag seine seine Ablehnung der Huldigungsmotette in der Liturgie gleich zu Amtsbeginn auch in diese Richtung gedeutet werden. Doch Burckard berichtet an dieser Stelle nicht von einer solchen politischen Implikation, und das, obwohl er sonst gerade politisch bedeutsame Rang- und Präzedenzfragen der Kardinäle und auswärtiger Herrscher lang und breit erörtert. ${ }^{47}$ Sehr wohl war aber Alexander VI. auch sonst um die Liturgie bemüht: In seiner Amtszeit brachte sein Zeremoniar Johannes Burckard gleich mehrfach den neuen Mess-Ordo heraus, und er selbst gab ein festliches Weihnachtsmissale in Auftrag. ${ }^{48}$

Hier mag ein Detail von Belang sein: Burckard bezeichnet Johannes Tinctoris nicht als Komponisten der Motette, sondern als Autor des Epigramms. Erst Arnold Schering geht davon aus, dass er zusätzlich auch der Komponist gewesen sei. ${ }^{49}$ Auch wenn Burckard den großen Meister als $\gg$ legum doctor[] atque music[us]« vorstellt, hat er den Text und nicht die $\mathrm{Mu}-$ sik vor Augen. Sollte auch die Musik von Tinctoris gestammt haben, so verwundert, dass sie nicht überliefert worden ist. Hier mag eine Rolle ge-

46 Marco Pellegrini, Ascanio Maria Sforza. La parabola politica di un cardinale-principe del rinascimento, 2 Bde. (durchgehend paginiert), Rom 2002 (Nuovi Studi Storici, 60), S. 382-392. Bereits bei seiner Ernennung zum Kardinal dankte Ascanio Sforza seinem damaligen Amtskollegen Rodrigo Kardinal Borgia, dem nachmaligen Papst. Vgl. ebda., S. 106 mit Anm. 117 sowie Marco Pellegrini, »Ascanio Maria Sforza: la creazione di un cardinale >di famiglia«", in: Gli Sforza, la Chiesa lombrada, la corte di Roma. Strutture e pratiche beneficiarie nel ducato di Milano (1450-1535), hrsg. von Giorgio Chittolini, Neapel 1989 (Europa mediterranea. Quaderni, 4), S. 215-298: S. 288 mit Anm. 250.

47 Vgl. Jörg Bölling, »Causa differentiae. Rang- und Präzedenzregelungen für Fürsten, Herzöge und Gesandte im vortridentinischen Papstzeremoniell«, in: Rom und das Reich vor der Reformation, hrsg. von Nikolaus Staubach, Frankfurt am Main u.a. 2004 (Tradition - Reform - Innovation, 7), S. 147-196.

48 J. Bölling, Das Papstzeremoniell der Renaissance (wie Anm. 3), S. 33f. (Lit.). Rezipiert wird fast ausschließlich der Druck von 1502, da dieser der vielzitierten einschlägigen Edition zugrunde liegt: »Ordo missae Ioannis Burckardi«, in: Tracts on the Mass, hrsg. von J. W. Legg, London 1904 (Henry Bradshaw Society, 27), S. 119-178. Die Editio princeps stammt aber von 1496; vgl. etwa die Göttinger Inkunabel: Staats- und Universitätsbibliothek Göttingen, 8 H E RIT I, 7860 INC.

49 A. Schering, Musikalisches aus Joh. Burckards Liber notarum (wie Anm. 39), S. 174: »Der Text - und wohl auch die Musik - stammt von keinem geringeren als Johannes Tinctoris ...«. 
spielt haben, dass er in erster Linie als Musiktheoretiker geachtet wurde, als »musicus«, wie auch Burckard ihn nennt. Nicht auszuschließen ist aber auch, dass die Musik mehr oder minder improvisiert vorgetragen wurde - am Metrum orientiert wie einst die Modalnotation, aber auch spätere Kompositionen. Möglicherweise teilte die Tinctoris-Motette deren Schickal: Philologisch prosodisch einwandfrei, doch musikalisch äußerst medioker, in ihrer gleichsam hämmernden Homorhythmik und statischen Homophonie für längere Zeit sogar kaum ertragbar, erschienen diese Kompositionen in der Tat eher ihres Textes als ihrer Musik wegen erinnernswert. ${ }^{50}$ Auch die Qualität literarischer und musikalischer Formen und Gattungen des Liedes konnte sehr divergieren, indem anspruchsvolle Texte schlechte Vertonungen und herausragende Kompositionen mittelmäßige Texte aufwiesen. ${ }^{51}$ So mag auch hier der Text im Vordergrund gestanden haben und die Musik nebensächlich gewesen sein: Klangvoll war bereits der durch Burckard schriftlich verbürgte Name des Musiktheoretikers, da bedurfte es keiner Aufführung mehr. ${ }^{52}$ Möglicherweise ist der Text sogar nie in Form einer Motette erklungen, erhielt seine Performanz allein durch die Übergabe des Schriftstücks, vergleichbar den zahlreichen Buchgeschenken, die dem Papst gemacht wurden, darunter literarische und wissenschaftliche Werke, aber auch Messendrucke, die den Akt der Übergabe in Form von Widmungsbildern festgehalten oder zumindest ihrerseits mit den Mitteln der bildenden Kunst in Szene gesetzt haben. ${ }^{53}$

Diese Überlegung gewinnt durch eine Beobachtung des Göttinger Mittel- und Neulateiners Bernhard Schirg zusätzlich an Plausibilität: An einer

$50 \mathrm{Zu}$ diesem Themenkomplex siehe insbesondere Thomas Schmidt-Beste, »Verse metre, word accent and rhythm in the polyphonic hymn of the fifteenth century «, in: Studi musicali 28 (1999), S. 363-396; ders., Textdeklamation in der Motette des 15. Jahrbunderts, Turnhout 2003.

51 Vgl. etwa den Tagungsband Gattungen und Formen des europäischen Liedes vom 14. bis zum 16. Jahrhundert, hrsg. von Michael Zywietz, Volker Honemann und Christian Bettels, Münster u. a. 2005.

52 Zum Verhältnis von Schrift und Performanz am Papsthof siehe J. Bölling, Das Papstzeremoniell der Renaissance (wie Anm. 3), pass., insbes. S. 91-106; zum grundlegenden Problem vormoderner Medialität von Musik in Text und Performanz siehe ders., Musicae utilitas (wie Anm. 43), S. 248-254.

$53 \mathrm{Zu}$ denken ist dabei unter anderem an die Widmungsbilder der Messenbücher von Elzéar Genet (genannt Carpentras), Andrea Antico, Cristobál de Morales, Giovanni Pierluigi da Palestrina und Francesco Soriano. Siehe dazu Daniel Glowotz, »Repräsentation und Papsthuldigung in der römischen a cappella-Messe des 16. und 17. Jahrhunderts «, in: Kirchenmusikalisches Jabrbuch 92 (2008), S. 25-36: S. 34f.; R. Köhler, Die Cappella Sistina (wie Anm. 12), S. 212, Abb. 5; K. Pietschmann, Kirchenmusik zwischen Tradition und Reform (wie Anm. 6), Abb. 3 (I-Rvat 611 , fol. $\left.1^{v}\right)$. 
Stelle des 1497 von Pietro Lazzaroni verfassten Carmen ad Alexandrum VI heißt es: »Romam Veterem concesserat ille / Lectus Alexandro orator « »Das Roma vetus (Altehrwürdiges Rom) überließ der handverlesene Botschafter dem (Papst) Alexander« (Laz. Alex., 1, 214f) ${ }^{54}$ Schirgs Forschungen legen nahe, dass mit den Worten »Romam Veterem « der fragliche Motettentext gemeint war und dieser dem Papst bereits am 6. Dezember 1492 durch den als Botschafter fungierenden venezianischen Humanisten Sebastiano Badoer hatte überreicht werden können. Seine Information erhielt Lazzaroni offenbar von Giasone del Maino. Dieser hatte nicht nur dieselbe Funktion des Botschafters für Mailand wie Baoder für Venedig inne, sondern war als Professor für Jura an der Universität Pavia ein Kollege Lazzaronis, der dort Rhetorik lehrte. ${ }^{55}$ Laut Burckard nahm Maino zusammen mit dem Grafen Sforza und zwei weiteren Mailänder Botschaftern an jenem Papstgottesdienst teil, in dem die Motette hätte erklingen sollen, und zwar »in loco oratorum laicorum «, am Ort der weltlichen Botschafter. ${ }^{56}$ Spätestens in der Amtszeit von Burckards Nachfolger Paris de Grassis (15041521) wäre für weltliche Gesandte wie diese unter Umständen ein Platz unmittelbar rechts neben dem Papstthron in Frage gekommen, wenn sie einen entsprechend hohen persönlichen Rang hätten geltend machen können oder eine persönlich Ehrung durch den Papst hätten genießen dürfen. Doch mit der Angabe »in loco oratorum laicorum« ist eindeutig jener zwischen Cancelli und Kardinalsbänken liegende schmale Streifen gleich links hinter dem Eingang zum Presbyterium gemeint - also weit weg vom Papst. Um die Möglichkeit, den Papst persönlich anzugehen, noch weiter zu verringern, rückte Paris de Grassis die Bank der Kardinäle sogar sogar unmittelbar an die Wand, obgleich er damit die sonst von ihm so gelobte, in der Bodenmarmorierung vorgegebene Symmetrie partiell aufgab. ${ }^{57}$ Burckards Fassung des Kurienzeremoniales hingegen war in dieser Hinsicht noch eindeutig: Weltliche Botschafter, die des Kaisers, der Könige, der Fürsten und anderer Potentaten, sitzen, sofern sie nicht selbst den persönlichen Rang eines Prälaten einnehmen, am besagten Ort zwischen Chorgitter und Kardinals-

54 Siehe dazu demnächst Bernhard Schirg, Die Ökonomie der Dichtung. Das Carmen ad Alexandrum VI des Pietro Lazzaroni, 1497.

55 Ebda.

56 Vgl. Johannis Burckardi Liber Notarum, hrsg. von Celani (wie Anm. 39), Bd. 1, S. 376, Z. 29 S. 377, Z. 1.

57 Vgl. dazu ausführlich J. Bölling, Das Papstzeremoniell der Hochrenaissance (wie Anm. 34), S. 292-295. 
bank. ${ }^{58}$ Die Botschafter machten Burckard zufolge im Unterschied zu zahlreichen späteren Gesandten keinerlei Anstalten, einen anderen als diesen Ort auch nur zu erwägen. Sie selbst nahmen den vorgesehenen Platz ohne die sonst so ausführlich bezeugten Streiterein ein: »se locaverunt«, wie Burckard lakonisch schreibt. ${ }^{59}$ Es bestand für die Mailänder Delegation vor diesem Hintergrund gar keine andere Möglichkeit, dem Papst den Motettentext des Tinctoris zu überreichen, als bei der vorausgehenden Audienz ihres venezianischen Kollegen. Dass sie jeden Versuch unterließen, an den Thron heranzurücken, könnte zudem als weiteres Indiz dafür gedeutet werden, dass dem Papst das Schriftstück bereits vorlag. Nur die von ihm dann abgelehnte Aufführung der Motette war noch denkbar und wurde daher vom Mailänder Kardinal Sforza versucht. Ob dann nach dem Gottesdienst noch, wie vom Papst in Aussicht gestellt, Musik zum Text erklang, bleibt hingegen offen.

Tinctoris' Text besteht aus Versen, die abwechselnd sechs und fünf Hebungen aufweisen, einen Hexameter und einen Pentameter mit Zäsur - Distichen, wie sie kennzeichnend für Epigramme sind, die dem besonderen Lob eines Herrschers dienen. Bis auf das abschließende Wort »Amen« und die - allerdings nur beiläufige - Erwähnung Gottes erinnert nichts an ein Gebet:

Epigramma Joannis Tinctoris legum doctoris atque musici, in laudem et gloriam SS. D. N. [Sanctissimi Domini Nostri] Alexandri Pape VI.:

Gaude Roma vetus magnis celebrata triumphis

Cui Deus eternum contulit imperium.

Claris Cesaribus quondam regnata fuisti,

Multo clarior es subdita presulibus,

Qui virtute licet nituerunt tempore prisco,

Haud vincunt etas quem modo nostra videt.

Sextus Alexander Hispanus origine celsa

Regnat et officio fungitur ethereo;

Qui prudens, justus, constans, pius atque modestus

Pro meritis tanto culmine dignus erat.

Eya christicole Domino persolvite grates

Quilibet, et vestrum mente pia resonet:

Vivat Alexander celebrandus imagine Magni,

Fastigio major, non probitate minor.

Amen.

58 Vgl. ebda. und Marc Dykmans (Hrsg.), L'xuvre de Patrizi Piccolomini ou cérémonial papal de la première Renaissance, 2 Bde., Vatikanstadt 1980-1982 (Studi e Testi, 293-294), S. 462, Nr. 1433 (Z. 15-17).

59 Johannis Burckardi Liber Notarum, hrsg. von Celani (wie Anm. 39), Bd. 1, S. 377, Z. 1. 
Freu Dich, altehrwürdiges Rom, gefeiert in großen Triumphen, Dem Gott ewige Herrschaft übertrug.

Von glänzenden Caesaren warst Du einst beherrscht worden, Um vieles glänzender bist $\mathrm{Du}$ (nun), unterworfen den Bischöfen.

Diejenigen, welche in alter Zeit freilich vor Tugend leuchteten, besiegen nicht jenen, den unser Zeitalter zu sehen bekommt.

Alexander der sechste, Spanier, von hoher Herkunft,

Herrscht und versieht sein himmlisches Amt;

Klug, gerecht, standhaft, fromm und maßvoll wie er ist,

War er um seiner Verdienste willen eines solchen Gipfels würdig.

Auf, Ihr Christen, sagt Dank dem Herren

Alle, und in Eurem frommen Gemüt möge widerhallen:

Es lebe Alexander, zu feiern im Abbild (Alexanders) des Großen, Größer an Hohheit, nicht kleiner an Redlichkeit.

Amen.

Die antike Größe Roms wird heraufbeschworen: die Triumphzüge siegreicher Feldherren und der Glanz kaiserlicher Herrschaft. Der Hinweis in Vers 2, Gott selbst habe Rom ewige Herrschaft übertragen, rekurriert auf die antike klassische Dichtung der Kaiserzeit in Verbindung mit der etablierten Lehre von der Abfolge der Weltreiche: Das Imperium Romanum galt nach christlicher Auffassung als das letzte Reich vor der Wiederkunft Christi, bis $1453 \mathrm{im}$ Osten und im Rahmen der Translatio Imperii auch weiterhin im Westen bestehend - als »Heiliges Römisches Reich ${ }^{60}$ Daher konnte kein weiteres Reich kommen - bis auf das Himmelreich. Im christlichen Glauben ist aber nur dieses ewig, »eternum«. Bei der Formulierung »eternum contulit imperium « handelt es sich folglich um eine konkrete Anspielung auf Vergils Aeneis, jenes bedeutendste Epos des römischen Altertums, in dem der heidnische Göttervater Iuppiter den Romanhelden Aeneis beauftragt, Rom zu gründen, eine Stadt, der ewige Herrschaft beschieden sei: »imperium sine fine ${ }^{61}$ Das Wort »imperium« wird im Motettentext dem klassischen Vorbild entsprechend als personenbezogene kaiserliche Herrschaft, nicht als die später institutionalisierte Form eines »Reiches«verstanden. Es bedarf daher keiner Bemühung der Konstantinischen Schenkung, um den Papst als Herrscher über Rom darzustellen: Wie die folgenden Verse zeigen, ist er es in noch größerem Maße als seine antiken Vorgänger. Das gilt nicht nur für die

60 Vgl. Stefan Weinfurter, »Wie das Reich heilig wurde: um 1157«, in: Die Macht des Königs. Herrschaft in Europa vom Frühmittelalter bis in die Neuzeit, hrsg. von Bernhard Jussen, München 2005, S. 190-204; Barbara Stollberg-Rilinger, Das Heilige Römische Reich Deutscher Nation. Vom Ende des Mittelalters bis 1806, München 2006, S. 10f.

61 Vergil, Aeneis, 1, 279. Vgl. P. Vergili Maronis opera, hrsg. von Roger A. B. Mynors, Oxford 1969, S. 111. 
römische, sondern auch für die griechische Antike: Mit deren Hauptexponenten, Alexander dem Großen, teilt Alexander VI. nicht nur den Namen mehr noch, er übertrifft ihn sogar an Größe, ohne ihm an Rechtschaffenheit nachzustehen.

Der Vorrang des Textes vor der Komposition wird um so deutlicher, wenn man Überlieferungssituationen anderer Motetten mit in den Blick nimmt, bei denen die Verhältnisse umgekehrt sind. So weist etwa Heinrich Isaacs Motette Sancti Spiritus assit nobis gratia / Imperii proceres, die im Jahre 1507 auf dem Reichstag in Konstanz erklang, in beiden überlieferten Handschriften zwar sangliche Melodien der Einzelstimmen, doch ein an zahlreichen Stellen korrumpiertes hexametrisches Versmaß auf. ${ }^{62}$ Erstaunlicherweise erweist sich dabei die Basler Fassung - abgesehen von einzelnen Wendungen - als weitaus schlechter. ${ }^{63}$ Erstaunlich ist dies zum einen deshalb, weil der Handschriftenerwerb gemäß einem Eintrag auf der ersten Seite des gesamten Kodex auf das besondere Interesse des Humanisten Jakob Salzmann zurückzuführen ist, der sich lateinisch-griechisch antikisierend $»$ Jacobus Salandronius « nannte, ${ }^{64}$ zum anderen, weil es sich um die nachweislich ältere Handschrift handelte: Bereits 1510 hatte Salzmann Basel verlassen, so dass er den Band vorher erhalten haben muss. ${ }^{65}$ Die Annaberger, heute in

62 Vgl. Basel, UB Basel, Mus. ms. F IX 55, fol. $4^{\mathrm{v}}-7^{\mathrm{r}}$ sowie Dresden, SLUB Dresden, Mus. 1-D505, p. 516-519. Neueditionen auf dieser Handschriftengrundlage bieten Martin Staehelin, Die Messen Heinrich Isaacs, 3 Bde., Bern und Stuttgart 1977 (Publikationen der Schweizerischen Musikforschenden Gesellschaft; 2, 28), Bd. 2, S. 77; Thomas Schmidt-Beste, »Die humanistische Staatsmotette. Probleme und Möglichkeiten der Edition alter Musik«, in: Produktion und Kontext, hrsg. von H. T. M. van Vliet, Tübingen 1999, S. 91-109: S. 103f. (sowie Abb. If., S. 106-109); ders., »Carmina laudatoria. Humanistische Panegyriken als Textvorlagen für Staatsmotetten der Renaissance«, in: Acta Conventus Neo-Latini Abulensis. Proceedings of the Tenth Congress of Neo-Latin Studies, hrsg. von Rhoda Schnur u. a., Tempe 2000, S. 585-596: S. 589f. (hier ohne kritischen Apparat) sowie zuletzt Victoria Panagl, Lateinische Huldigungsmotetten für Angehörige des Hauses Habsburg. Vertonte Gelegenheitsdichtung im Rahmen neulateinischer Herrscherpanegyrik, Frankfurt am Main u.a. 2004 (Europäische Hochschulschriften. Reihe XV: Klassische Sprachen und Literaturen, 92), S. 45-59. Eine im Rahmen meines Habilitationskolloquiums vorgestellte neue kritische Edition bereite ich zur Publikation vor.

63 Vgl. die Edition bei V. Panagl, Lateinische Huldigungsmotetten (wie Anm. 62), S. 52-54. Einigen Experten gilt gleichwohl die Basler Handschrift als die bessere Abschrift. Siehe etwa T. Schmidt-Beste, Die humanistische Staatsmotette (wie Anm. 62), S. 99.

64 Vgl. Basel, UB Basel, Mus. ms. F IX 55, fol. $\mathrm{I}^{\mathrm{r}}$.

65 T. Schmidt-Beste, Die humanistische Staatsmotette (wie Anm. 62). S. 98 mit Anm. 18. Zur Person siehe Martin Bundi, »Salzmann, Jakob«, in: Historisches Lexikon der Schweiz (http://www.hls-dhs-dss.ch), No. 5. Für wertvolle weitere Informationen, auf die an anderer Stelle ausführlich einzugehen ist, sei Prof. Dr. Martin Staehelin, Göttingen, und Dr. Michael Jucker, Luzern, herzlich gedankt. 
Dresden verwahrte und in der älteren DTÖ-Ausgabe noch nicht berücksichtigte Handschrift, deren besonders vertrauenswürdige Vorlage anscheinend für den sächsischen Kurfürsten Friedrich den Weisen bestimmt war, ist weitaus jüngeren Datums. ${ }^{66}$ Die neue CMM-Edition von 2011 übernimmt aus dieser Handschrift die Gliederung der Motette in vier Teile, indem $\gg \mathrm{Im}$ perii proceres in drei weitere Abschnitte unterteilt wird, bietet aber eine weder sprachlich-syntaktisch noch metrisch-prosodisch zufriedenstellende Textfassung. ${ }^{67}$ Ganz offensichtlich steht bei beiden Manuskripten die Musik, nicht der Text im Vordergrund. Im diametralen Gegensatz zur Überlieferung der Tinctoris-Motette bei Burckard gibt es zur Aufführung von Isaacs Werk in keiner erhaltenen schriftlichen Quelle einen expliziten Hinweis, nicht einmal in den Reichstagsakten. ${ }^{68}$ Die ursprüngliche Funktion der Motette ist aber allein ihrem eigenen, fehlerhaft überlieferten Text nach zu bemessen. Dessen Bedeutung kann somit im Rahmen der überlieferten Reichstagsquellen wiederum nicht hoch genug eingeschätzt werden: Hier handelt es sich schließlich um einen situationsbedingt formulierten Appell Maximilians an die Reichsstände und an den amtierenden, allerdings nur in der Annaberger Handschrift explizit genannten Papst Julius II. - ein politisches Programm des Herrschers zur Eröffnung des Reichstages. ${ }^{69}$ Der Über-

66 Vgl. Dresden, SLUB Dresden, Mus. 1-D-505, S. 516-519; T. Schmidt-Beste, Die humanistische Staatsmotette (wie Anm. 62). Zum Text der DTÖ-Ausgabe siehe insbes. Martin Just, Studien zu Heinrich Isaacs Motetten, 2 Bde., Diss. mschr. Tübingen 1960, Bd. 1, S. 66f. und S. 157-159 sowie Bd. 2, S. 10f. und S. 69f. Just ist letztlich die Berücksichtigung der Dresdner Handschrift zu verdanken; vgl. Albert Dunning, Die Staatsmotette 1480-1555, Utrecht 1970, S. 38 Anm. 3. Den problematischen Begriff »Staatsmotette« kritisiert zu Recht L. Lütteken, Guillaume Dufay und die isorhythmische Motette (wie Anm. 17), S. 264f.

67 Heinrich Isaac, Opera omnia, hrsg. von Edward Lerner, Bd. 11, Motets, Teil 2, Nr. 41, S. 124 135. An der Stelle »nobiles rector « findet sich ein nicht ins Versmaß passender Kretikus, Formulierungen wie »pater patrem« oder »Germania virtus« ergeben keinen rechten Sinn. An einigen Stellen fehlt die für einen Hexameter erforderliche sechste Hebung.

68 Diesen Hinweis verdanke ich Herrn Dr. Dietmar Heil, Bearbeiter der Reichstagsakten von 1507. Ihm und Herrn Prof. Dr. Eike Wolgast als Leiter des Editionsprojektes »Deutsche Reichstagsakten« sei darüber hinaus vielmals für die überaus großzügige Erlaubnis gedankt, die in der Forschungsstelle in Regensburg zusammengetragenen Quellen und sogar die bereits vorliegenden Korrekturfahnen des 2014 erscheinenden Bandes einsehen zu dürfen: Dietmar Heil (Bearb.), Deutsche Reichstagsakten unter Maximilian I., Bd. 9: Der Reichstag zu Konstanz 1507 (Deutsche Reichstagsakten. Mittlere Reihe, Bd. 9, hrsg. von der historischen Kommission bei der Bayerischen Akademie der Wissenschaften durch Eike Wolgast, München 2014.

69 In der älteren Literatur wird dieser Bezug zu Papst Julius II. noch nicht gesehen, da die in der Dresdener Handschrift verbürgte Lesart »Iuli« der bis dahin ausschließlich bekannten Variante »Iube« des Basler Kodex aus sprachlich-metrischen wie musikalisch-kompositorischen Gründen vorzuziehen ist. 
sicht halber sei der Text hier noch einmal abgedruckt - zumal sich an einigen Stellen Abweichungen gegenüber den bisherigen Publikationen ergeben und im fünfletzten Vers aus prosodischen Gründen eine Konjektur, eine von keiner Handschrift verbürgte Emendation, erforderlich ist: ${ }^{70}$

\author{
Prima pars \\ Sancti Spiritus assit nobis gracia! \\ Illustrator ades summo delapsus Olimpo, \\ Ignis amorque, Deus, qui Spiritus omnia reples, \\ Respice concilii cetum, Constancia felix \\ Quem tenet. Imperii rebus, pie, consule, rector. \\ Ut celo pacem dictas, sic federa terris \\ Auspice te Cesar componat Maximilianus. \\ Secunda pars \\ Imperii proceres, Romani gloria regni, \\ Vos electores, vos archiepiscopi et omnes \\ Pontifices, totus simul ecclesiasticus ordo, \\ Armorumque duces, vos langraviique potentes, \\ Marchio quisquis ades, comes et baro nobilis, urbis \\ Rector seu populi, imperio quem federa iungunt: \\ Consulite in medium, rebus succurrite fessis, \\ Ecclesiam fulcite sacram; concordia sancto \\ Vos stringat vinclo, propriis et rebus adeste. \\ Auscultate pio pro vobis Maximiliano \\ Sollicito. Accedas [nobis], favor optime Iuli, \\ Qui pater es patrum. Populos frenare superbos, \\ $\mathrm{Da}$, Deus. Imperii iustis cadat emulus armis. \\ Hinc tibi devotas reddamus carmine grates, \\ Atque tuas laudes celebret Germanica virtus. \\ Amen.
}

Die Gnade des Heiligen Geistes stehe uns bei!

Gleite vom Gipfel des Olymps hernieder und sei als Erleuchter zugegen,

Du Feuer und Liebe, Gott, der Du als Geist alles erfüllst,

70 In jedem Fall müssen bei den Worten »Ecclēsia « und »Maximilianus« nachklassische Kürzungen der Naturlänge $» \bar{e} \ll$ bzw. der Positionslänge $» l i \ll$ in Kauf genommen werden. Durch das hier konjizierte Wort »nobis« im der fünftletzten Vers erhält der Hexameter die obligatorischen sechs Hebungen. Dieses Wort könnte aufgrund des in den Handschriften fast identisch ausgeführten Wortes »vobis« im voraufgehenden Vers ausgelassen worden sein. Alternativ könnte der Vers auch gelautet haben: »Sollicito. Accedas, favor, optime maxime Iuli«, wobei das Wort »maxime« aufgrund des vorhergehenden »Maximiliano« hätte versehentlich ausgelassen werden können - zumal in der sicher zu verwerfenden, doch belegten, auf Maximilian zu beziehenden Variante »Iube« (vgl. voraufgehende Anm.). Zu den bereits vorliegenden und der geplanten Edition siehe oben Anm. 62. 
blicke auf den versammelten Reichstag, den das glückliche Konstanz beherbergt. Nimm Dich, gütiger Lenker, der Angelegenheiten des Reiches an.

Wie Du dem Himmel Frieden gebietest, so möge auf Erden

Maximilian als Kaiser unter Deiner Leitung Bündnisse schließen.

Ihr Vornehmsten des Heiligen Reiches, Zierde des Römischen Reiches, Ihr Kurfürsten, Ihr Erzbischöfe und all Ihr Bischöfe, der gesamte geistliche Stand zugleich, Ihr Herzöge und ihr mächtigen Landgrafen, jeder anwesende Markgraf, edler Graf und Freiherr, Stadt- oder Landesherr, den Bündnisse an das Reich binden, beratet Euch für das Allgemeinwohl! Helft in der Not!

Stützt die heilige Kirche! Eintracht verbinde Euch mit heiligem Band, und nehmt Euch auch der eigenen Belange an!

Hört auf den gütigen Maximilian, der um Euch besorgt ist! Trete uns bei, Du beste Gunst, Julius, der Du Vater der Väter bist! Die hochmütigen Völker zu zügeln, Gewähre, Gott! Der Feind des Reiches möge durch gerechte Waffen zu Fall kommen.

Daher wollen wir Dir ergebenen Dank im Lied darbringen, und Deinen Lobpreis verbreite die deutsche Tugend.

Amen.«

Vergleicht man die beiden Motetten, die des Tinctoris und die des Isaac, so weisen Form, Funktion und Rezeption gegenläufige Tendenzen auf: Gaude Roma vetus ist als formal tadelloser Text ohne Noten überliefert, in seiner ursprünglich angedachten Funktion aber vom Adressaten selbst, dem Papst persönlich, abgelehnt worden. Imperii proceres mit der vorausgehenden, erweiternd in Verse umgeschmiedeten Pfingstsequenz weist hingegen eine formal durchaus eindrucksvolle Komposition auf, deren überlieferter Text aber entstellt und deren ursprüngliche Funktion nur aus dessen Inhalt im Abgleich mit verschiedensten zeitgenössischen Quellen sowie aus der späteren Rezeption zu erschließen ist. Der von der musikwissenschaftlichen Forschung zwischenzeitlich als eigenständige Motette erachtete erste Teil erklang - späteren Zeugnissen nach zu urteilen - wahrscheinlich rahmend vor und nach dem eröffnenden Heilig-Geist-Amt am 30. April 1517, von dem der Bericht des venezianischen Botschafters Vincenzo Quirini spricht. ${ }^{71}$ Der

71 Vgl. D. Heil, Deutsche Reichstagsakten unter Maximilian I. (wie Anm. 68), Nr. 658 (kommentierte kritische Edition der Handschriften Venedig, Biblioteca Marciana, Cod. marc. ital. VII/989 [= 9581], fol. 19 ${ }^{\mathrm{r}}-20^{\mathrm{r}}$ sowie Venedig, Biblioteca della Fondazione Querini Stampalia, Cl. IV, Cod. V [ $=769]$, fol. $\left.90^{v}-91^{v}\right)$. Dass dieses später als obligatorisch erachtete, ursprünglich aus den Feierlichkeiten zum Krönungstag des Königs hervorgegangene Heilig-Geist-Amt 
zweite Teil schloss sich wohl unmittelbar an die Wiederholung des ersten Teils nach dem Gottesdienst an. ${ }^{72}$ Im Text dieses zweiten Teils ist der Herrscher nicht Objekt der Huldigung, wie bei Tinctoris' Text Papst Alexander VI., der dann noch abwiegelnd reagiert. Vielmehr firmiert Maximilian selbst als handelndes Subjekt, indem er durch seine Hofkapelle ein politisches Programm verlautbaren lässt. Die Motette hätte keinem der angesprochenen Reichsstände allein überreicht werden können, wie es bei Tinctoris' Text offenbar gegenüber dem Papst der Fall gewesen war. Sie sollte ihre Wirkung im Erklingen entfalten. Dass die Aufführung dieser Motette keinen Eingang in die Reichstagsakten gefunden hat und nur über den besagten Bericht eines auswärtigen Botschafters zu rekonstruieren ist, der als Venezianer nicht unmittelbar in die inneren Belange des Reichstags eingebunden war, widerspricht Maximilians intendierter Funktion nicht, denn ihre angedachte Wirkung hat die Komposition auch im Reich nicht verfehlt - zumindest nachträglich: Kein Geringerer als Kurfürst Friedrich der Weise, der auf dem Reichstag durchaus in Opposition zum Kaiser die Interessen der Stände vertrat, zeigte für seine Kapelle Interesse an dem Text, und der Humanist Jakob Salzmann ließ sich weder von der kaiserkritischen Opposition der räumlich naheliegenden Eidgenossen, zu denen auch Basel gehörte, noch vom äußerst korrumpierten lateinischen Text abstoßen. Beide Personen, Friedrich der Weise wie Jakob Salzmann, hatten die präsumtive Aufführung der Motette selbst nicht miterleben können, da sie an diesen eröffnenden Zeremonien nachweislich nicht teilnahmen. ${ }^{73}$ Den Eidgenossen bot sich allenfalls im Rahmen des für sie nachgeholten Empfangs eine Gelegenheit: Maximilian lud sie eigens zur Sonntagsmesse am 16. Mai ins Konstanzer Münster, die dem Chronist Diepold Schilling zufolge »durch den wichbischoff von Costentz und von der künglichen maiestat organisten und sengern sollichermaß und so loblich, costlich und herlich angefangen und volbracht, das darvon nit ist ze schriben. $\ll^{74}$

dieser Quelle zufolge tatsächlich stattgefunden hat, ist für die ersten Reichstage des späten 15. und frühen 16. Jahrhunderts sonst nicht so ohne weiteres belegbar. Zum Wormser Reichstag von 1495 etwa vgl. Barbara Stollberg-Rilinger, Des Kaisers alte Kleider. Verfassungsgeschichte und Symbolsprache des Alten Reiches, München 2008, S. 3 lf.

$72 \mathrm{Zu}$ dieser hier nicht weiter zu erörternden Frage bereite ich eine eigene Publikation vor (vgl. oben Anm. 62).

73 Kurfürst Friedrich der Weise traf ebenso verspätet ein wie die Delegation der Eidgenossen; vgl. D. Heil, Deutsche Reichstagsakten unter Maximilian I. (wie Anm. 68), Nr. 189, Punkt 1, und Nr. 722, Punkte 1, 7 und 9, ferner, Nr. 709 (Teilnehmerverzeichnis).

74 Ebda., Nr. 722, Punkt 9. Vgl. dazu auch die Abbildung in Die Schweizer Bilderchronik des 
So sehr gerade die auswärtigen Gäste sich von der Performanz des Reichstags beeindruckt zeigten, so wenig Geschriebenes hinterließen sie darüber. Umso wichtiger werden die erhaltenen Texte - ungeachtet ihrer philologisch dürftig überlieferten Gestalt.

Neben diesen beiden Motetten, einer für Alexander VI. und einer weiteren für Julius II., sei noch die dritte angekündigte, für Leo X. bestimmte vergleichend hinzugezogen: Heinrich Isaacs Optime pastor. Wie Klaus Pietschmann überzeugend nachweisen konnte, wurde dieses Werk nicht am Papsthof ${ }^{75}$ sondern zum Empfang des päpstlichen Nuntius Lorenzo Campeggi am Innsbrucker Hof Maximilians I. im Jahre 1514 aufgeführt. ${ }^{76}$ Diese Erkenntnis beruht zum einen auf der Dekonstruktion einer vorschnellen Kombination von unterlegtem Motettentext und Tagebucheintrag des Zeremonienmeisters Paris de Grassis, zum anderen neben vielen weiteren Beobachtungen auf der Rekonstruktion durch Analogieschluss: Die an sich für Fragen der Musik völlig unerheblichen, jedoch generell geltenden zeremoniellen Rang- und Präzedenzregelungen ermöglichen andere als die bisher für verbindlich erachteten Akteure, so dass sich der gesamte Aufführungskontext verschiebt. ${ }^{77}$

Zusammenfassend lässt sich festhalten, dass in der päpstlichen Liturgie offenbar keine Huldigungsmotetten aufgeführt wurden. Motetten, die enkomiastische Züge mit Blick auf einzelne Päpste erkennen lassen, erhielten ihre Performanz ( $o b$ in klingender oder schriftlich dargebrachter Form) entweder außerhalb Roms, wie die letzten beiden Kompositionen, oder im Papstpalast, so etwa Gaude Roma vetus. Dieser Befund wird durch einen weiteren Hinweis Johannes Burckards bestätigt: Nach der Krönung Julius' II. huldigten die Sänger dem neuen Pontifex mit ihren Gesang - nicht im Gottesdienst, sondern nach dem Essen, und zwar vor dessen Kammer, wobei die Türen geöffnet waren. ${ }^{78} \mathrm{Ob}$ es sich um eine Motette oder ein einfaches Ständchen handelte, geht aus Burckards Angaben leider nicht hervor nur dass, soweit er informiert sei, ein jeder der Sänger einen französischen

Luzerners Diebold Schilling 1513, 2 Bde.: Faksimile und Kommentarband, hg. von Alfred A. Schmid, Luzern 1977-1981, Bd. 1, fol. 233v .

75 So noch A. Dunning, Die Staatsmotette (wie Anm. 66), S. 45-53.

76 K. Pietschmann, Politisierte Vokalpolyphonie am Hof Maximilians I. (wie Anm. 39).

77 Siehe zu diesen beiden speziellen Punkten ebda., S. 131f. und S. 136f.

78 Johannis Burckardi Liber Notarum, hrsg. von Celani (wie Anm. 39), Bd. 2, S. 414, Z. 18f.: »Prandio facto, venerunt cantores capelle et cantarunt ante cameram pape, aperto ostio«; vgl. B. Schimmelpfennig, Die Funktion der Cappella Sistina (wie Anm. 20), S. 146, Nr. 10a und S. Žak, Cappella - castello - camera (wie Anm. 30), S. 202, Anm. 139. 
Scudo vom Papst erhalten habe. ${ }^{79}$ Alle übrigen Motetten, die sich auf einen bestimmten Papst beziehen lassen, sind Gebetsmotetten, etwa Dulcis amica mea von Gaspar van Weerbeke (um 1445 - nach 1517) für Innozenz VIII., ${ }^{80}$ Ad honorem tuum, Christe von Compère für Julius II., ${ }^{81}$ sowie Gaude felix Florentia und Letare sancta mater ecclesia für die Medici-Päpste Leo X. und Clemens VII. ${ }^{82}$

Auf der Ebene der Verschriftlichung von Kompositionen und Zeremonien sind mit Blick auf die wechselseitige Interdependenz nur Analogieschlüsse möglich. Alle genannten Motetten waren im päpstlichen Palast aufführbar, zugleich aber auch in den päpstlichen Kirchen und Kapellen, deren Vorbild die Cappella Sistina darstellte. ${ }^{83}$ Für die Frage nach der Performanz von Korporationen und Kompositionen sind somit nicht nur für die Messensätze, sondern auch für Motetten die liturgisch-zeremonialen $\mathrm{Zu}$ sammenhänge näher zu untersuchen.

\section{Die Performanz von Korporationen und Kompositionen}

Die gängigen räumlichen Stratifikationsmuster des Papstzeremoniells haben für die Aufführung von Motetten keine Bedeutung: Wie bereits eingangs erwähnt, wurden aufwändige Textvertonungen unabhängig von Rang- und Präzedenzfragen gesungen - sei es auf der vom sonstigen Kapellraum räumlich abgetrennten Sängerkanzel, sei es im ohnehin nicht dem öffentlichen Zeremoniell unterliegenden, nur einem handverlesenen Personenkreis zugänglichen Papstpalast. In die zeitliche Stratifikation hingegen waren Motetten vielfach eingebunden - im Rahmen des Adventus-Zeremoniells sogar

79 Johannis Burckardi Liber Notarum, hrsg. von Celani (wie Anm. 39), Bd. 2, S. 414, Z. 19f.: »et papa, ad informationem nostram, fecit dari cuilibet I scutum regis Francie.«

80 Helmut Hucke, »Die Musik in der Sixtinischen Kapelle bis zur Zeit Leos X.«, in: Zusammenhänge, Einflïsse, Wirkungen (wie Anm. 24), S. 154-167: S. 161 mit Anm. 22f. Zur hier einschlägigen handschriftlichen Überlieferung von CS 15, fol. 204 $-208^{\mathrm{r}}$, siehe R. Sherr, The Papal Chapel (wie Anm. 25), S. 211.

81 H. Hucke, Die Musik in der Sixtinischen Kapelle (wie Anm. 80), ebda.; R. Sherr, The Papal Chapel (wie Anm. 25), S. 227, Nr. III (zu CS 42, fol. $15^{\mathrm{v}}-19^{\mathrm{r}}$ ).

82 Siehe dazu Bonnie J. Blackburn, »Music and Festivities at the Court of Leo X: A Venetian View«, in: Early Music History 11 (1992), S. 1-37: 30-32, und Edward Lowinsky, »A newly Discovered Sixteenth-Century Motet Manuscript at the Biblioteca Vallicelliana at Rome«, in: Journal of the American Musicological Society 3 (1950), S. 173-232: S. 197; neu abgedruckt in: Edward Lowinsky, Music in the Culture of the Renaissance and Other Essays, hrsg. von Bonnie J. Blackburn, 2 Bde., Chicago 1989, S. 433-482: S. 451.

83 Vgl. oben Anm. 34. 
in tonangebend strukturierender, kommentierender oder gar performativer Funktion. ${ }^{84}$ Innerhalb der gottesdienstlichen Liturgie wiederum scheinen die Motetten auf den ersten Blick eine eher untergeordnete Rolle gespielt zu haben, zumindest was die äußere Gestalt des Ritus und dessen Gültigkeit betrifft. Gleichwohl bildeten sie vielfach auch hier wichtige Zeremonien ab und verhalfen dieser zu einer affektiv-emotionalen Wirkung. So hat Richard Sherr gezeigt, dass die musikalische Faktur der Tractus-Vertonung Domine, non secundum exakt auf den Ablauf der liturgischen Zeremonien abgestimmt war, insbesondere auf den Gang des Papstes zu seiner Kniebank. ${ }^{85}$ Doch der Zeremoniar Johannes Burckard kritisierte die Ausführung dieses Tractus in Form einer polyphonen Motette $-»$ in figuris « - am Aschermittwoch, dem 4. März 1495, da diese Vortragsweise in der Fastenzeit von allen als blasphemisch empfunden worden sei. ${ }^{86}$ Folglich nahmen Komponist und Sänger aus eigenem Antrieb weitaus mehr Rücksicht auf die räumlichen Zeremonien der Liturgie, als der Zeremoniar auf die polyphonen Möglichkeiten der Musik. Burckards beiläufige Bemerkung sollte jedoch nicht zur allgemein gültigen Norm verabsolutiert werden. Sein Nachfolger Paris de Grassis ließ mehrstimmige Musik im Jahre 1514 sogar auf dem Höhepunkt von Fastenund Passionszeit, dem Triduum Sacrum, zu - eine Haltung, die noch im 18. Jahrhundert zur Legitimation dieser Aufführungspraxis herangezogen werden sollte. ${ }^{87}$ Gleichwohl hat dieser Zeremoniar seine Auffassung in den folgenden Jahren grundsätzlich geändert ${ }^{88}$ - ganz im Sinne seines ihm sonst so verhassten, hier freilich von ihm unerwähnt gelassenen Amtsvorgängers

84 Vgl. J. Bölling, Musicae utilitas (wie Anm. 43), S. 231-248.

85 Richar Sherr, »Illibata Dei Virgo Nutrix and Josquin's Roman Style«, in: Journal of the American Musicological Society 41 (1988), S. 434-464: 450-453.

86 Johannis Burckardi Liber Notarum, hrsg. von Celani (wie Anm. 39), Bd. 1, S. 578, Z. 4f.: »Cantores cantarunt tractum et Sanctus in figuris etc.; et male fuit, quia ab omnis blasphematus «; vgl. B. Schimmelpfennig, Die Funktion der Cappella Sistina (wie Anm. 20), S. 150 und R. Köhler, Die Cappella Sistina (wie Anm. 12), S. 120 mit Anm. 803 sowie insbes. S. 123f. mit Anm. 830, ferner S. 154 mit Anm. 1040. Der Ausdruck »in figuris« bezieht sich ungeachtet der Kursivsetzung durch den Editor Celani wohl gleichermaßen auf Sanctus und Tractus.

$87 \mathrm{Vgl}$. A. Adami, Osservazioni per ben regolare il coro (wie Anm. 5), S. 37.

88 Siehe bereits Richard Sherr, »The Singers of the Papal Chapel and Liturgical Ceremonies in the Early Sixteenth Century. Some Documentary Evidence«, in: Rome in the Renaissance. The City and its Myth, hrsg. von Paul A. Ramsey, Binghamton (New York) 1982 (Medieval and Renaissance texts and studies, 18), S. 249- 264: 256; ferner ders., »Ceremonies for Holy Week, Papal Commissions, and Madness (?) in Early Sixteenth-Century Rome«, in: Music in Renaissance Cities and Courts. Studies in Honor of Lewis Lockwood, hrsg. von Jesse Ann Owens und Anthony M. Cummings, Warren (Massachusetts) 1997 (Detroit Monographs in Musicology. Studies in Music, 18), S. 391- 403. 
Burckard. Dieser Verzicht ist für die Dauer der Fastenzeit insofern nur konsequent, als er auch für die Totenämter galt: Mehrstimmige Requiem-Vertonungen waren selbst bei Trauergottesdiensten für Papst und Kardinäle nicht vorgesehen und sind wohl deshalb auch notenmäßig nicht überliefert. Eine gewisse Ausnahme bildeten lediglich Sängerbegräbnisse, bei denen allerdings auch das Responsorium »Libera me« in mehrstimmiger Ausführung gestattet war - nicht als Teil der Kapellliturgie, sondern auf dem anschlieBenden Weg zum Grab. ${ }^{89}$

Wo nicht Gesänge der Liturgie, sondern lediglich der Liturgie entlehnte verschiedene, neu miteinander kombinierte Texte vertont worden sind, gibt weniger die musikalische Faktur als die Kombination dieser Texte und deren Traditionskontext Aufschluss über die musikalische Performanz. Klaus Pietschmann hat dies etwa am Beispiel der Motette Ecce advenit Dominator eindrucksvoll gezeigt: Nicht die in der älteren Forschung angegnommene Papstkrönung Clemens' VII., sondern die Kaiserkrönung Karls V. war der zeremonielle Ort dieser Motette. ${ }^{90}$ Die angesprochenen Herrscherpersönlichkeiten mussten dabei nicht anwesend sein, sondern konnten durch Repräsentanten vertreten werden. Dies zeigen Klaus Pietschmanns bereits erwähnte Forschungen zur Aufführung von Isaacs Motette Optime Pastor, die sich an Papst Leo X. wendet, jedoch entgegen älteren Vorstellungen nicht in Rom erklang, sondern am kaiserlichen Hof in Innsbruck. ${ }^{91}$ Ebenso richtete sich Isaacs zur Eröffnung des Konstanzer Reichstags 1507 erklungene Motette Sancti Spiritus assit nobis gratia / Imperii proceres an einer Stelle an Papst Julius II., obgleich dieser in Rom weilte. ${ }^{92}$

Um diesen eingeschlagenen Weg weiterzugehen, erscheinen zwei verschiedene Möglichkeiten denkbar: Entweder man geht von den Motettentexten aus und versucht, den liturgischen oder im weitesten Sinne zeremoniell gebundenen Ort dieser Kompositionen zu ergründen, oder man geht umgekehrt von den Zeremonienbüchern aus und überlegt, welche Stellen auf den Einsatz von Motetten schließen lassen und sucht erst dann nach geeigneten Kompositionen. Die erste Methode ist bereits ausgiebig angewandt worden und gehört in den traditionellen Bereich historischer Musikwissen-

89 Vgl. R. Köhler, Die Cappella Sistina (wie Anm. 12), S. 105f. und S. $125 f$.

90 Klaus Pietschmann, »Eine Motette zur Kaiserkrönung Karls V. von Costanzo Festa«, in: Iberoromania 54 (2001), S. 30-52; überarbeitet und übersetzt als: »A Motet by Costanzo Festa for the Coronation of Charles V«, in: Journal of Musicological Research 21 (2002), S. 319-354.

91 Ders., Politisierte Vokalpolyphonie am Hof Maximilians I. (wie Anm. 39).

92 Siehe oben Anm. 76f. 
schaft, wo durch einschlägige fächerübergreifende Kenntnisse und Methodenkompetenz bereits wichtige Ergebnisse erzielt werden konnten. ${ }^{93}$ Hilfreich erscheint hier zum einen die Unterscheidung zwischen den strikt anlassbezogenen und den lediglich anlassgebundenen Motetten im Anschluss an Laurenz Lütteken, ${ }^{94}$ zum anderen die Differenzierung nach Rafael Köhler in drei Gruppen: erstens liturgisch-gregorianische, zweitens kompilierte oder paraphrasierte und drittens neu gedichtete Texte. ${ }^{95}$ Die zweite Methode hingegen richtet sich insbesondere an die Geschichtswissenschaft und die historisch-liturgiewissenschaftlichen Fächer der Theologie, da es zunächst um die Geschichte von Liturgie und Zeremoniell und vor diesem Hintergrund um den möglichen Einsatz von Musik geht.

Deshalb gilt es in diesem Beitrag, von den Texten der liturgischen und zeremonialen Bücher auszugehen und von dort aus fächerübergreifend die überlieferten konkreten Motetten näher zu betrachten. Den Zeremonienbüchern der Renaissance zufolge lassen sich ephemere, okkasionelle und reguläre Anlässe unterscheiden. Bei den ephemeren Gelegenheiten sind die Kompositionen anlassbezogen, das heißt nur bei diesem einmaligen Anlass aufführbar, bei den okkasionellen und regulär kirchlich-liturgischen, höfischfestlichen und diplomatisch-protokollarischen Feierlichkeiten hingegen anlassgebunden, das heißt bei einem derartigen Anlass möglich und bei erneuter Gelegenheit wiederholbar. Neudichtungen kommen vor allem bei den ephemeren Anlässen in Frage, gregorianische Texte in der regelmäßig gefeierten Liturgie, Kompilationen und Paraphrasen letztlich bei allen Gelegenheiten. In zunehmenden Maße ist darüber hinaus eine Unterscheidung zwischen sakraler und säkularer Sphäre feststellbar. Die Zeremoniare machen dies ihrer Zuständigkeit entsprechend meist am Raum, an der Kleidung und vor allem an der Form und Funktion der jeweiligen Zeremonien fest. Hier wird, zumindest in Ansätzen, das Bemühen um eine Unterscheidung zwischen kirchlicher Liturgie auf der einen und höfischem, zugleich städtisch sowie diplomatisch geprägtem Zeremoniell auf der anderen Seite erkennbar - mit Auswirkungen auch auf die Musik..$^{96}$ An einigen Beispielen

93 Siehe oben Anm. 13.

94 Zur Unterscheidung von anlassbezogenen und anlassgebundenen Kompositionen siehe L. Lütteken, Guillaume Dufay und die isorhythmische Motette (wie Anm. 17), S. 156f. (zu Motetten), S. 265 (zu Musik allgemein) und S. 427 (zusammenfassend).

95 R. Köhler, Die Cappella Sistina (wie Anm. 12), S. 155-166.

96 J. Bölling, Das Papstzeremoniell der Renaissance (wie Anm. 3), S. 79-112; ders., »Liturgia di cappella e cerimonie di corte «, in: Pompa sacra. Lusso e cultura materiale alla corte papale nel basso medioevo (1420-1527), hrsg. von Thomas Ertl, Rom 2010 (Nuovi Studi Storici, 86), S. 37-53. 
soll nun diese ephemere, okkasionelle und reguläre Verwendung von Motetten erörtert werden.

$\mathrm{Zu}$ den ephemeren Gelegenheiten zählen die bereits besprochenen Ereignisse: eine der ersten Messen des neu gewählten Papstes Alexander VI. im Jahre 1492, die Eröffnung des Konstanzer Reichstages durch den gewählten Kaiser Maximilian I. 1507 und der Empfang des Nuntius Papst Leos X. am kaiserlichen Hof in Innsbruck 1514. ${ }^{97}$ Von besonderer Bedeutung ist in diesem Zusammenhang aber auch eine Motette, die schon viele Fragen aufgeworfen hat: Sola caret monstris (CS 42). Ihr offenbar gegen die Feinde Frankreichs gerichteter, selbst den Papst kritisch angehender Text scheint auf einen Kompositionszeitpunkt nach 1511 zu deuten, dem Jahr der Heiligen Liga, obgleich das Chorbuch bereits 1507 angelegt worden war. Das Werk hätte dann aber dem Kodex nachträglich beigebunden worden sein müssen. ${ }^{98}$ Doch dem paläographischen Befund nach zu urteilen erfolgte die Abschrift dieser Motette spätestens im selben Jahr 1507 oder allenfalls $1510,{ }^{99}$ so dass der vermutete politische Bezug ausscheidet.

Wie aber ist dann mitten am Papsthof die gegenüber Julius II. formulierte Kritik zu erklären? Zunächst einmal ist zu berücksichtigen, dass der Pontifex keineswegs als $»$ das wilde Tier Julius $\ll^{100}$ bezeichnet wird, da es sich beim Wort »Iuli« am Ende des ersten Verses nicht um einen Genitiv, sondern um einen Vokativ handelt. ${ }^{101}$ Somit beginnt der Text mit einer kritischen Frage, die sich, dem französischen König in den Mund gelegt, direkt an den amtierenden Papst richtet: »Wenn allein Gallien frei von Ungeheurn ist, warum, Julius, quält dann mit seinen Zähnen dieses abscheuliche wilde Tier unser Königreich?« Doch wer ist mit dem Tier gemeint? Dafür kommen verschiedene Möglichkeiten in Frage. Sucht man an Julius II. festzu-

97 Siehe dazu oben Abschnitt II.

98 Vgl. A. Dunning, Die Staatsmotette (wie Anm. 66), S. 85 Anm. If.; R. Sherr, The Papal Chapel (wie Anm. 25), S. 229 mit Anm. I.

99 Vgl. die unterschiedlichen Datierungen bei R. Köhler, Die Cappella Sistina (wie Anm. 12), S. 159 mit Verweis in Anm. 1076 auf Jeffrey Dean, The Scribes of the Sistine Chapel, Diss. Chicago 1984, S. 236, sowie zuletzt Richard Sherr, »What Were They Thinking? Sola caret monstris at the Papal Court«, in: Essays on Renaissance Music in Honour of David Fallows, hrsg. von Fabrice Fitch und Jacobijn Kiel, Woodbridge 2011, 163-169: S. 164 Anm. 6.

100 A. Dunning, Die Staatsmotette (wie Anm. 66), S. 84.

101 Das betont mit Kritik an A. Dunning zu Recht R. Köhler, Die Cappella Sistina (wie Anm. 12), S. 159 mit Anm. 1077; vgl. den Text bei A. Dunning, Die Staatsmotette (wie Anm. 66), S. 84: "Sola caret monstris si Gallia, cur modo Iuli / Dentibus hoc nostrum torquet fera pessima regnum «. Vgl. dazu auch oben in Anm. 69f. den analogen Fall in besagter Mottete Heinrich Isaacs. 
halten, so muss man davon ausgehen, dass die Motette diesem Papst selbst nie zu Ohren gekommen sei, weil man sie nur außerhalb der offiziellen Papstliturgie gesungen habe - als geistiges Eigentum der Sänger, die sich über ihren Dienstherrn hinter dessen Rücken hätten lustig machen wollen. ${ }^{102}$ Ein korporativer Text der Sänger ohne Performanz im Papstgottesdienst also! Problematisch an dieser Deutung ist aber, dass Motetten des Chorbuchs 42 der liturgischen Ordnung des Kirchenjahres folgen, darunter die erwähnte Motette Ad honorem tuum, Christe, ${ }^{103}$ und die fragliche Komposition Sola caret monstris sich unter dem dritten Fastensonntag, Oculi, findet. Es ist Richard Sherrs Verdienst, die mannigfaltigen Bezüge der liturgischen Lesungstexte und gängigen Predigtmotive dieses Tages mit dem Motettentext freigelegt und damit die angebliche Kritik an Julius II. widerlegt zu haben. ${ }^{104}$ Von besonderem Gewicht ist dabei sein Hinweis auf die biblische Grundlage der liturgischen Lesungen und der musikalischen Motette: die Täuschung Jakobs, sein von ihnen verkaufter Sohn Joseph sei von einem wilden Tier getötet worden - der Motettentext spricht von »fera pessima« (vgl. Genesis 37, 1-34). Ob jedoch seine Vermutung zutrifft, es handele sich bei diesem Tier um König Ludwig XII., so dass die Motette nicht antipäpstliche, sondern in $»$ reverse psychology« anti-französische Züge trage, ${ }^{105}$ sei dahingestellt.

Mindestens drei Mächte scheinen zunächst mindestens ebenso gut in Frage zu kommen: Venedig, das Reich oder Spanien. Gegen Venedig verbündeten sich Frankreich, das Reich und Spanien bereits 1508 in der Liga von Cambrai. ${ }^{106}$ Der unbekannte Autor des Motettentextes könnte auf das dann 1511 erfolgte Bündnis zwischen Papst und Frankreich hingearbeitet haben. Dafür fehlen jedoch die nötigen Anhaltspunkte. Einen vielleicht noch bedeutenderen Gegner Frankreichs hingegen bildete das Heilige Römische Reich deutscher Nation: Maximilian I. beanspruchte das formal zum Reich gehörende Mailand und suchte es im Rahmen seines geplanten Romzuges dem französischen Einfluss zu entziehen. Dieses Anliegen machte er 1507 sogar zu einem zentralen Gegenstand des bereits erwähnten Reichstags von

102 Jeffrey Dean, »The occasion of Compère's Sola caret monstris«, in: Musica disciplina 40 (1986), S. 99-133: S. 129f.

103 Siehe oben Anm. 81.

104 R. Sherr, Sola caret monstris at the Papal Court (wie Anm. 99), S. 164-169.

105 Ebda., S. 169.

106 Neidhard Bulst, »Ludwig XII. (1498-1514)«, in: Französische Könige und Kaiser der Neuzeit. Von Ludwig XII. bis Napoleon III. 1498-1870, München 1994, S. 24-51: S. 47f. 
Konstanz. ${ }^{107}$ Das Reich und auch Venedig kommen aber insofern eher nicht in Frage, als es zu keinerlei kriegerischen Handlungen gekommen ist. Für den fraglichen Entstehungszeitraum des Chorbuchs zwischen 1504 und 1507, spätestens 1510, war genau dies jedoch bei einer in deutschen Publikationen oft übersehenen Macht der Fall: Ferdinand II. von Aragón. Hatte dieser im Jahre 1501 noch eine Teilung des Königreichs Neapel mit dem französischen König beschlossen, so nahm er dieses 1503 als ganzes für sich in Anspruch und konnte seine Herrschaft bis 1507 festigen. ${ }^{108}$ Der poetische Motettentext, der erste Teil in stichischen Hexamtern, der zweite in zwischen Hexameter und Pentameter wechselnden Distichen, könnte als Replik auf Lorenzo Buonincontros (1410-1500) Lehrgedicht auf Ferdinand (Ferrante) I. von Neapel (1431-1494) angelegt worden sein. Darin preist der Autor die Kriege Ferrantes gegen Frankreich und hebt dies sogar durch eine eigenhändig gesetzte Überschrift hervor. ${ }^{109}$

Geht man aber vom Bibeltext selbst aus, so erscheint das wilde Tier als bloß erdachte Chimäre: Der Betrug in der Josephsgeschichte besteht ja gerade darin, dass die Brüder anstelle ihres Verrats und Verkaufs ein wildes Tier erfinden, um nicht selbst aufzufliegen. Diese Chimäre des Tieres konnte im politischen Kontext als Chiffre für den unnötigen, trugreichen, selbst familiäre Bindungen verletzenden Krieg der verschiedenen Mächte untereinander aufgefasst werden. War Frankreich seinerzeit im Innern von Kriegen weithin verschont geblieben, ${ }^{110} »$ sola caret monstris «, so wütete dieses Monstrum unentwegt im Italien der Renaissance. Die Korporation der »cantores « hatte offenbar als Schmelztiegel der Nationen soviel Eigengewicht gewonnen, dass sie sich Kritik und Einflussnahme in einem Ausmaß leisten konnte, wie es traditionell nur einem Hofnarr, einem »buffone «, zugestanden worden wäre. ${ }^{111}$ Zugleich zeigt sich dabei anscheinend eine der

107 Vgl. oben Anm. 68

108 Miguel Angel Ladero, Das Spanien der katholischen Könige. Ferdinand von Aragon und Isabella von Kastilien 1469-1516, Innsbruck 1992, S. $282 \mathrm{f}$.

109 Vgl. Stephan Heilen (Hrsg.), Laurentius Bonincontrius Miniatensis, De rebus naturalibus et divinis. Zwei Lehrgedichte an Lorenzo de' Medici, Stuttgart u.a. 1999 (Beiträge zur Altertumskunde, 129), II, 3, 493 (S. 624) sowie die vom Autor selbst gesetzte Überschrift in dessen Autograph: »De bello Ferdinandi cum Gallis et rebellibus sibi« (ebda., S. 625; zum Codex S. 20-47, zum Nachweis als Autorgraph ebda., S. 22-31, insbes. S. 31 mit Anm. 89).

$110 \mathrm{Vgl}$. N. Bulst, Ludwig XII. (wie Anm. 106), S. 50f.

111 Das Amt des buffone, das bei verschiedenen Zeremonien in Erscheinung tritt, unter Alexander VI. sogar - wohl zum Aufgebot Cesare Borgias gehörend - bei Fronleichnamsprozessionen, bedarf noch der intensiveren Erforschung. Siehe dazu etwa B. Schimmelpfennig, Die Funktion der Cappella Sistina (wie Anm. 20), S. 135, und den Kommentar von Sabine Zak, ebda., S. 17lf. 
letzten großen Aktionen französischer Interessenvertreter am Papsthof: Nach der Überwindung des Schismas und der Konsolidierung des Papsttums in Rom fanden auch zahlreiche Italiener, Spanier, Deutsche und Engländer Aufnahme in das Sängerkollegium der päpstlichen Kapelle und vermochten ihr Repertoire ebenso wie dessen Aufführungspraxis durch regelrechte Nationalstile zu prägen. Innerhalb der Kapelle der Avignonesischen Päpste und Gegenpäpste hatten hingegen Franzosen den Ton angegeben. ${ }^{112}$ Dieser Umstand wiegt einmal mehr, wenn man bedenkt, dass die Motette Compère zugeschrieben ist: Die Sänger, womöglich sogar nur die "galli«, wählten für die Aufnahme in ihr repräsentatives, in Reinschrift angelegtes Chorbuch und für ihren performativen Vortrag am Papsthof einen Text in der Vertonung des bevorzugten Komponisten vom französischen Hof.

Dass der Motettentext hier eine eher frankophile als etwa germanophile Haltung einnahm, entsprach jedoch nicht nur der ursprünglichen Zusammensetzung des Sängerkollegiums, sondern auch der späteren politischen Ausrichtung der Papsttums: Waren die Verbindungen zwischen Papst Leo X. und König Franz I. sehr intensiv, ${ }^{113}$ so kaum es mit vielen Reichsteilen zum Bruch, konfessionell durch die Reformation, militärisch schließlich durch den Sacco di Roma im Jahre 1527. Die musikalische Form der Motette konnte somit zwei verschiedene Funktion zugleich einnehmen: zum einen die eines Ventilators partieller Interessen innerhalb der Kurie, zum anderen die eines Ventils innerer Spannungen nach außen hin, ohne die von der Liturgie vorgegebenen Texte zu verletzen. Dadurch wurde die regelmäBige Wiederverwendung der Motette als Repertoire der regulären Gottesdienste der Liturgie möglich: Sie war damit dauerhaft, aus dem Rahmen fallend, ephemeres Zeugnis einer regulären Praxis.

An okkasionellen Gelegenheiten sind etwa Friedensverkündigungen zu nennen. Dem feierlichen Anlass entsprechend stimmt der Papst jenen Gesang an, der sonst nur an Sonn- und Festtagen im Stundengebet erklingt, wenn in der Messe der Gesang des Gloria vorgesehen ist: das Te Deum. ${ }^{114}$ Darüber hinaus ist aber auch ein Psalmvers vorgesehen, der hier zwar nur ein gesprochenes Gebet bildet, doch zugleich auch in zahlreichen Motetten

112 Vgl. oben Anm. 24-27.

113 Vgl. Götz-Rüdiger Tewes und Michael Rohlmann (Hrsg.), Der Medici-Papst Leo X. und Frankreich. Politik, Kultur und Familiengeschäfte in der europäischen Renaissance, Tübingen 2002 (Spätmittelalter und Reformation. Neure Reihe, 19).

114 M. Dykmans, L'œuvre de Patrizi Piccolomini (wie Anm. 58), S. 178, Nr. 490. Siehe auch Sabine Žak, »Das Tedeum als Huldigungsgesang«, in: Historisches Jahrbuch 102 (1982), S. 1-32: S. 27 mit Anm. 102f. 
begegnet: »Non nobis Domine, non nobis, sed nomini tuo da gloriam.« (Psalm 113, 9 der Vulgata / Psalm 115,1 der Luther-Bibel). ${ }^{115}$ Die $\gg$ cantores « mögen mit solchen Motetten das Motto des mittelalterlichen Templerordens aufgegriffen haben. Noch die Renaissancepäpste sahen den Kreuzzug als ihre Pflicht an. ${ }^{116}$ Umgekehrt, vom Repertoire der Sixtinischen Kapelle aus, betrachtet, kämen ihrem Text nach ersatzweise auch Kompositionen in Frage, die den Frieden heraufbeschwören oder feiern, etwa das anonym überlieferte Werk Pacis in terris (CS 15) ${ }^{117}$ und die Motette Quis numerare (CS 15) von Loyset Compère (um 1450-1518). ${ }^{118}$ Sind all diese mehrstimmigen Vertonungen also an der vom Zeremonienmeister vorgesehenen Stelle aufgeführt worden? Wir wissen es nicht, da es für die Zeremoniare nicht weiter von Belang war, sofern der Ablauf der liturgisch und juridischkanonistisch verbindlichen Zeremonien ungestört vonstatten gehen konnte. Daher ist es durchaus denkbar, dass die entsprechenden Motetten nur in der »cappella parva der Sänger oder gar, wie bereits Gaude Roma vetus, im Papstpalast erklangen. Entscheidend ist, dass die Sänger ihren Gesang als Beitrag ihrer eigenen Korporation vortrugen: Dabei traten sie zunächst einmal um dieser selbst willen in Erscheinung und brachten die Texte zum Klingen, sei es in der kirchlichen Liturgie oder dem höfischen Zeremoniell. Liturgisch wirkten sie entweder stellvertretend für die gesamte Kurie in der täglich genutzten »cappella parva oder aber in der »cappella magna«, der Sistina, wo sie mit ihrer Sängerkanzel eine eigene Art von Kapelle in Anspruch nahmen, so dass sie in Papstgottesdiensten außerhalb der Sistina entweder eine entsprechende Tribüne oder aber eine eigene Kapelle zugewiesen bekamen. ${ }^{119} \mathrm{Im}$ Rahmen des rein höfischen Zeremoniells des Palastes, das für diese Motetten ebenfalls in Frage kommt, galten nur die unmittelbaren Vorgaben des Papstes. Die Sänger hatten hier keine eigene liturgisch-zeremonielle Funktion und trugen wahrscheinlich auch andere, weltli-

115 M. Dykmans, L'œuvre de Patrizi Piccolomini (wie Anm. 58), S. 178, Z. $14 f$.

$116 \mathrm{Zu}$ Alexander VI. vgl. etwa Ludwig von Pastor, Geschichte der Päpste seit dem Ausgang des Mittlalters. Mit Benutzung des Päpstlichen Geheim-Archivs und vieler anderer Archive, 16 Bde. in 22, Freiburg im Breisgau ${ }^{7} 1925-1933$, Bd. 3,1, Freiburg 1924, S. 546-561 (zum »Türkenkrieg«). Siehe auch Adalbert Roth, »L'homme armé, le doubté turcq, l'ordre de la Toison d'or. Zur >Begleitmusik< der letzten großen Kreuzzugsbewegung nach dem Fall von Konstantinopel«, in: Feste feiern im Mittelalter, hrsg. von Detlef Altenburg und Jörg Jarnut, Sigmaringen 1991, S. 469-480.

117 R. Sherr, The Papal Chapel (wie Anm. 25), S. 212 zu CS 15, fol. $231^{\mathrm{v}}-235^{\mathrm{r}}$.

118 Vgl. H. Hucke, Die Musik in der Sixtinischen Kapelle (wie Anm. 80), S. 161 mit Anm. 21.

119 J. Bölling, Das Papstzeremoniell der Renaissance (wie Anm. 3), S. 140-144. 
che Kleidung. Das lassen zumindest die Einschärfungen der Zeremoniare und auch die Sängerstatuten erkennen, innerhalb der Liturgie hätten sie unbedingt Talar und Rochett beziehungsweise Supperpelliz zu tragen. ${ }^{120}$ Darstellungen späterer Jahrhunderte verdeutlichen diese bereits als altehrwürdig erachtete Unterscheidung in Abbildungen (vgl. Abbildungen 2 und 3). ${ }^{121}$

Wie wenig Bedeutung Motetten gegenüber ihrer Verwendung in der Amtszeit Dufays im frühen 15. Jahrhundert hatten, mag eine genauere Untersuchung ihrer Verwendung im Rahmen einer weiteren okkasionellen Feier verdeutlichen: der seit 1300 begangenen Heiligen Jahre. ${ }^{122}$ Johannes Burckard entwarf für das Heilige Jahr 1500 eine Ordnung, die bis zum Heiligen Jahr 1950 fast unverändert ihre Gültigkeit behalten sollte und auch in den in Folge des Zweiten Vatikanischen Konzils (1962-65) erneuerten Zeremonienbüchern für 1975, 1983 und 2000 nachwirkt. ${ }^{123}$ Auch hier war das Te Deum der entscheidende Gesang: Er markierte den Moment, in dem der Papst die Heilige Pforte durchschritt. ${ }^{124}$ Doch hier wie auch an allen anderen Stellen diente Musik in erster Linie der öffentlichkeitswirksamen Strukturierung oder Kommentierung. ${ }^{125}$ Eine performative Funktion der Musik, mehrstimmiger Motetten gar, sucht man vergebens. Es wurden lediglich die üblichen Antiphonen gesungen. ${ }^{126}$ Ähnlich scheint es 25 Jahre später der Fall gewesen zu sein. Burckards Nachfolger Paris de Grassis legte Papst Clemens VII. eine Liste von Vorschlägen und Anfragen vor, die der Papst mit zu

120 Ediert von R. Köhler, Die Cappella Sistina (wie Anm. 12), 227f., $\$ 31$ des Fragments A in IRvat CS 687, fol. 146-153 (entspricht Kapitel XIX der Statuten von 1545): »De habitu honstesto deferendo $\ll$.

121 Diese Darstellungen und Erläuterungen durch F. Bonanni, La Gerarchia Ecclesiastica (wie Anm. 5), Abbildung 155 (bei S. 483: »Musico della Cappella Ponteficia«, mit Talar und Superpelliz) und Abbildung 156 (bei S. 483: »Musico fuori della Cappella«) sind bisher offenbar kaum zur Kenntnis genommen worden.

122 Siehe dazu ausfuihrlich J. Bölling, Das Papstzeremoniell der Renaissance (wie Anm. 3), S. 218- 221.

123 Vgl. Andrea Weinmann, »Sola fides salvat rusticum. Das Heilige Jahr 1500 aus der Sicht des päpstlichen Zeremonienmeisters Johannes Burckardus«, in: Rom und das Reich vor der Reformation hrsg. von Nikolaus Staubach, Frankfurt am Main u.a. 2004 (Tradition - Reform - Innovation, 7), S. 237-249.

124 A. Schering, Musikalisches aus Joh. Burckards Liber notarum (wie Anm. 39), S. 175; vgl. Johannis Burckardi Liber Notarum, hrsg. von Celani (wie Anm. 39), Bd. 2, S. 178-188; vgl. auch B. Schimmelpfennig, Die Funktion der Cappella Sistina (wie Anm. 20), S. 149. R. Köhler, Die Cappella Sistina (wie Anm. 12), S. 186 mit Anm. 1262, verweist auch auf die voraufgehenden Beratungen: Siehe dazu Johannis Burckardi Liber Notarum, hrsg. von Celani (wie Anm. 39), Bd. 2, S. 189.

125 Vgl. L. v. Pastor, Geschichte der Päpste (wie Anm. 116), Bd. 3,1, S. 606-610.

126 Siehe bereits ebda., S. 607f. 


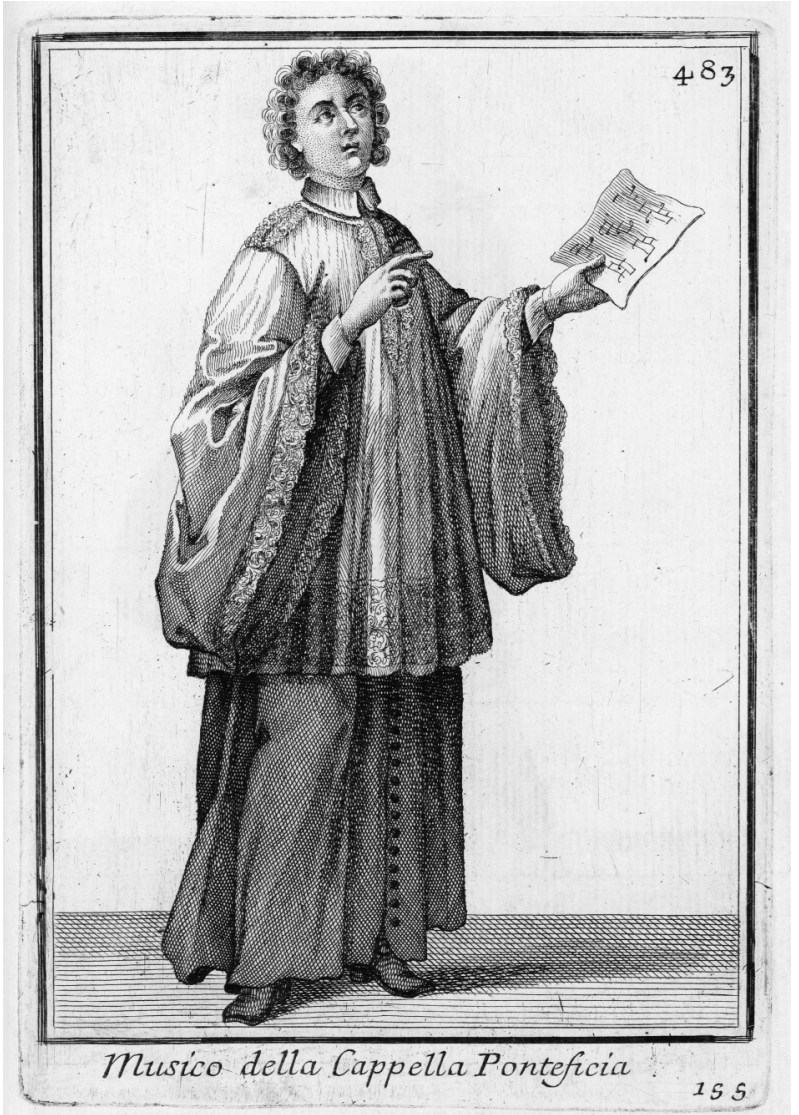

Abbildung 2: Filippo Bonanni, La Gerarchia Ecclesiastica ..., Rom 1720, Abb. Nr. 155 (bei S. 483) (Foto: Bildarchiv, SUB Göttingen)

stimmenden oder ablehnenden Kommentaren versah, was der Zeremoniar wiederum notierte. ${ }^{127}$ Auch hier diente die Vokalmusik in erster Linie der Strukturierung von Elementen wie der Präsentation des Schweißtuches der Veronika und des Abschlusses der gesamten Feier. ${ }^{28}$ Nimmt man nun noch

127 I-Rvat Vat. lat. 5634 I, fol. $238^{v}-240^{v}$ : »Pro clausura portarum aurearum quatuor in quatuor basilicis urbis pro fine jubilei consultetur papa «. Dieser Abschnitt findet sich nicht in der Fassung des Mucantius (ASV, Fondo Borghese, serie I 568); siehe dazu Marc Dykmans, »Paris de Grassi«, in: Ephemerides Liturgicae 100 (1986), S. 282-317: S. 317 (inhaltliche Paraphrase) und S. 332f. (»Appendice XXIII«, Teiledition).

$128 \mathrm{Vgl}$. I-Rvat Vat. lat. 5634 I, fol. 239": »Ostenso vultu sancto papa surgens et sine mitra stans intonet antiphonam > Cum iucunditate< etc. et cantores prosequantur cantantes usque ad porticum extra portam«, sowie ebda., fol. 240 ${ }^{\mathrm{r}}$ : »In fine ante himni cantum papa, qui semper mitratus fuit 


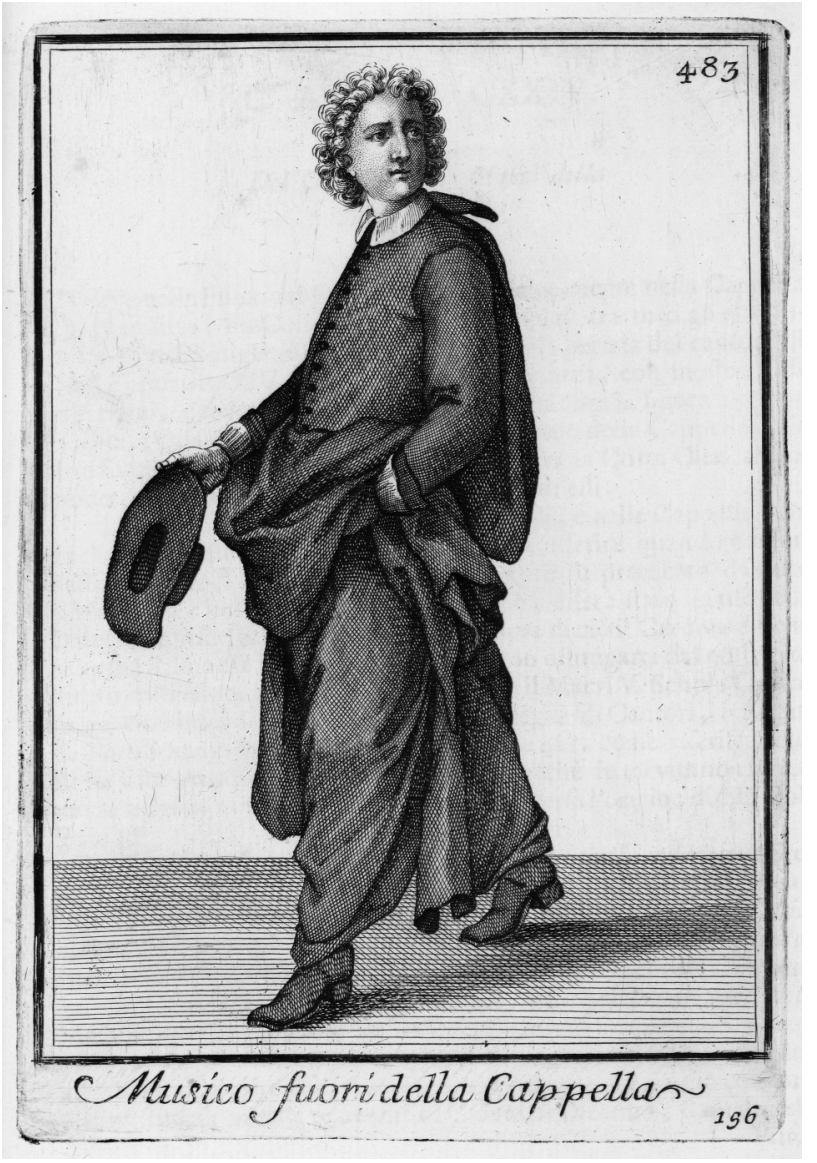

Abbildung 3: Filippo Bonanni, La Gerarchia Ecclesiastica ..., Rom 1720, Abb. Nr. 156 (bei S. 483) (Foto: Bildarchiv, SUB Göttingen)

die Tagebuchaufzeichnungen des nachfolgenden Zeremonienmeisters Biagio de Martinellis da Cesena und weitere Quellen hinzu, so steht fest: Es erklangen nach einigem Hin und Her ausschließlich einstimmige Gesänge, obgleich bestimmte Motetten geplant gewesen waren. ${ }^{129}$

Angesichts dieses ernüchternden Befundes zur okkasionellen Verwendung von Motetten erscheint deren ephemerer Einsatz umso bemerkenswerter: Die von Klaus Pietschmann eruierte archaische Struktur der Motette

sedensque in alta sede cum facula sua in manu descendit et accedens ad limen portae stans cum sua facula in manu intonat versum > Beata <etc., quem cantores prosequuntur usque ad finem.«

129 Vgl. dazu ausführlich J. Bölling, Das Papstzeremoniell der Renaissance (wie Anm. 3), S. $220 \mathrm{f}$. 
Optime Pastor etwa, die an die Zeit Dufays gemahnt und in dieser Tradition zugleich das konkrete Ereignis kommemorierend für die Zukunft festhält, ${ }^{130}$ entspricht der zeremoniellen Verwendung. Okkasionell wiederkehrende Anlässe hingegen wurden offenbar kaum für die Aufführung von Motetten genutzt.

Mehr noch als ephemere oder gar okkasionelle Ereignisse bot aber der dritte erwähnte Bereich die Möglichkeit für mehrstimmige Textvertonungen: die reguläre Liturgie und die darauf Bezug nehmenden höfischen Feste. Feierlichkeiten bei Hofe bildeten vor allem die so genannten Epula oder Prandia, Festmähler, zu denen die Sänger selbst regelmäßig geladen wurden, um verköstigt und entlohnt zu werden und ihrerseits Musik erklingen zu lassen. Da diese Bankette eng an den liturgischen Kalender gebunden waren und unmittelbar vor, nach oder sogar in der Messe abgehalten wurden, scheinen sie liturgische Züge getragen zu haben. ${ }^{131}$ Allerdings wurden diese Festgelage nicht in einem Gottesdienstraum abgehalten, sondern in der Sala Regia, und innerhalb der Messe erfolgten Verköstigungen ausschließlich während der Predigt. ${ }^{132}$ Raum und Zeit waren damit nicht liturgisch: Für die Dauer der Predigt unterbrach der zelebrierende Priester die Liturgie, legte zeitweise sogar sein Messgewand ab. Folglich erhielten die Sänger ihre Erfrischung nicht nur außerhalb des Gottesdienstraumes, sondern auch außerhalb der Gottesdienstzeit. Innerhalb der Liturgie hingegen waren Motetten regulär vor allem an drei Stellen gefragt: nach dem Offertorium, bei der Elevation und nach der Communio - Gesänge und Zeremonien also, die in engstem Zusammenhang mit der Eucharistie standen.

Beim Offertorium ist für die Zeremoniare in erster Linie wichtig, dass Motetten nach dem Verklingen des kirchenamtlich-liturgisch vorgesehenen gregorianischen Gesangs die Zeit der Inzens mit Weihrauch überbrücken. Das gilt selbst für einen Ästheten wie Paris de Grassis. ${ }^{133}$ Gleichwohl wäre ohne diese bloße Zulassung der Mehrstimmigkeit die Entwicklung eines Motetten-Repertoires zum Offertorium, wie es im 17. und 18. Jahrhundert

130 Vgl. K. Pietschmann, Politisierte Vokalpolyphonie am Hof Maximilians I. (wie Anm. 39), S. 130 und $137 f$.

131 So fasst sie aus nachvollziehbaren Gründen R. Köhler, Die Cappella Sistina (wie Anm. 12), S. 188195 (»Liturgische Epula«) auf, insbes. S. 189: »Gerade im Zusammenhang mit den Banketten des päpstlichen Hofes wird die Ambiguität von liturgischem und höfischem Zeremoniell deutlich.«

132 Vgl. ebda., S. 190 mit Anm. 1294 sowie S. 302, Anm. 1288.

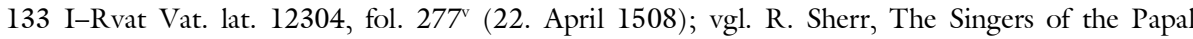
Chapel (wie Anm. 88), S. 255 mit Anm. 28. 
selbstverständlich war, ${ }^{134}$ nicht möglich gewesen, wenn nicht bereits Patrizi einen gravitätischen, sehr viel Zeit in Anspruch nehmenden Vollzug der Zeremonien gefordert ${ }^{135}$ und Paris de Grassis diese Regelung maßgeblich eingeschärft hätte. ${ }^{136}$ Aus der Sicht der Sänger liegt die eigentliche Leistung aber woanders: in der geistig-geistlichen Gabe ihrer direkt an Gott gerichteten gesungenen Gebete, die Fragen zeremonialer Ränkeleien ohnedies übersteigen - und daher in den maßgeblichen Schriftquellen unerwähnt geblieben sind. Dem zeitgenössischen Verständnis nach handelte es sich beim Offertorium nämlich keineswegs nur um eine Bereitung der Gaben im Sinne einer Vorbereitung. Im Zentrum der gesamten Zeremonien stand die erste Darbringung der Gaben, die damit dem menschlichen Zugriff für einen profanen Gebrauch entzogen waren. ${ }^{137}$ In der orthodoxen Liturgie, die wie die päpstliche Kapelle am altkirchlichen Verzicht auf Instrumente im Gottesdienst festhält, ${ }^{138}$ beginnt schon gleich nach dem Glaubensbekenntnis ana$\log$ zum »Offertorium « die »Anaphora mit einer Segnung der Gaben. ${ }^{139}$ Nur ein Teil dieses gesegneten Brotes wird in der Anaphora anschließend nun analog zum »Canon missae - konsekriert, während der zuvor lediglich gesegnete, nicht wandelnd geweihte Rest am Ende der Liturgie gereicht wird - als »Antidoron«, als »Ersatz« für all jene, die nicht zur Kommunion gegangen sind, da hierfür eine vorherige Beichte, besonderes Fasten und Nüchternheit am Tag des Empfangs erforderlich ist. ${ }^{140}$ Im frühmittelalterlichen Rom durfte sich nur ein einziger Sänger, der so genannte »archiparaphonista «, am materiellen Opfergang beteiligen, um die Aufführung des Gesangs nicht zu behindern. ${ }^{141}$ Dieser reichte als Gabe Weihwasser. ${ }^{142}$ Der anschließende Inzens mit Weihrauch hingegen war noch im Rom der Renaissance dem Diakon vorbehalten war, der zuvor das Evangelium vorgetra-

134 Vgl. Hartmut Möller, »Motetten nach dem Offertorium im 17. und 18. Jahrhundert«, in: Collectanea II (wie Anm. 2), S. 289-331.

135 Vgl. bereits Sabine Žak, »Sollemnis oblatio. Studien zum Offertorium im Mittelalter«, in: Kirchenmusikalisches Jabrbuch 72 (1988), S. 27-51: S. 44 mit Anm. 106.

136 J. Bölling, Das Papstzeremoniell der Renaissance (wie Anm. 3), S. 259-261.

137 J. Jungmann, Missarum Sollemnia (wie Anm. 8), Bd. 2, S. 3-125.

138 Zum »a cappella«-Ideal der Papstgottesdienste der »cappella papalis« in der Sixtinischen Kapelle siehe S. Žak, Cappella - castello - camera (wie Anm. 30), S. 213.

139 Vgl. Anastasios Kallis (Hrsg.), Liturgie. Die Göttliche Liturgie der Orthodoxen Kirche. Deutsch Griechisch - Kirchenslawisch, Mainz ${ }^{2} 1993$, S. 122f.

140 Vgl. ebda., S. 38 sowie S. 138 und 188; J. Jungmann, Missarum Sollemnia (wie Anm. 8), Bd. 2, S. 55-57 sowie S. 561f. (zu entsprechenden Traditionen im Frankenreich auch S. $562-564$ ).

141 J. Jungmann, Missarum Sollemnia (wie Anm. 8), Bd. 2, S. 39 mit Anm. 2lf.

142 Ebda. 
gen hatte. Paris de Grassis konzentriert sich seiner amtlichen Zuständigkeit entsprechend auf dessen Zeremonien und Körperhaltung, die eine Differenzierung des inzensierten Papstes als geistlichen Würdenträger und als in persona Christi handelnder Zelebrant zulasse. ${ }^{143}$ Noch deutlicher aber vermochten die parallel erklingenden Motettentexte solche Unterschiede zwischen Person und Amt, geistlichen und weltlichen Aspekten hervorzukehren. ${ }^{144}$ Ein reines »Bindeglied zur Präfation« bildeten die Motetten der »Meister der Polyphonie ${ }^{145}$ daher wohl in erster Linie aus der Perspektive der Zeremoniare. Welche immaterielle Gabe bot sich für die Sänger mehr an als ihre denkbar kunstvollste Musik!

Entsprechendes lässt sich zur Postcommunio festhalten: Ist der gregorianische Gesang einmal verklungen, wird die Aufführung mehrstimmiger Musik möglich, solange die Austeilung der Kommunion noch andauert. ${ }^{146}$ Hier nun geht es nicht um die Darbringung der Gaben, sondern um deren Empfang nach ihrer eucharistischen Wandlung. Die Musik bildet aus der Perspektive der ausführenden Korporation nicht nur eine begleitende Untermalung des Geschehens. Der zeitbedingten Praxis entsprechend, nur an hohen Festtagen und nach vorhergehender Beichte und Nüchternheit die in den Leib Christi gewandelte Hostie zu empfangen, war allgemein die so genannte "geistliche Kommunion ${ }^{147}$ üblich: der innerliche Mitvollzug des äußerlich wahrgenommenen, aber nicht persönlich, körperlich vollzogenen Sakramentsempfangs.

Bei Offertorium und Communio fanden Geben und Nehmen im Sinne des kultischen Darreichens und Empfangens ihren vornehmsten geistigen und geistlichen Ausdruck im Gesang der Motetten - für die Ausführenden ebenso wie für die mitvollziehenden Rezipienten. Die sonst so unterschiedlichen, partiell sogar gegenläufigen päpstlichen Reformmodelle von Assimilation, Distinktion und Partizipation im Sinne der Ideale von Virtus, Majestas und Indulgenz ${ }^{148}$ sind hier in besonders sinnfälliger Weise aufeinander bezo-

143 Vgl. J. Bölling, Das Papstzeremoniell der Renaissance (wie Anm. 3), S. 103 mit Anm. 49.

144 Ebda., S. 260f.

145 J. Jungmann, Missarum Sollemnia (wie Anm. 8), Bd. 2, S. 35.

146 Zur entsprechenden Analogie der liturgischen Zeremonien von Offertorium und Kommunion siehe J. Jungmann, Missarum Sollemnia (wie Anm. 8), Bd. 2, S. 427f. und S. 456.

147 Siehe dazu etwa Heinz Robert Schlette, Die Lehre von der geistlichen Kommunion bei Bonaventura, Albert dem Großen und Thomas von Aquin, München 1959 (Münchener theologische Studien, 2/7); Charles M. A. Caspers, »Magister consensus: Wessel Gansfort (1419-1489) und die Geistliche Kommunion«, in: Northern Humanism in European Context, 1469-1625. From the »Adwert Academy« to Ubbo Emmius, hrsg. von Fokke Akkerman, Arie Johan Vanderjagt und Adrie van der Laan, Leiden 1999, S. 82-98.

148 Siehe dazu den Beitrag von Nikolaus Staubach in diesem Band. 
gen: Liturgie und Musik haben gleichermaßen eine paränetische Vorbildfunktion, die auf pädagogische Prägung durch Nachahmung und Mitvollzug abzielt. ${ }^{149}$ Der Sängerchor partizipiert dabei entsprechend seiner distinkten Funktion im Modell der päpstlichen Majestas und gottesdienstlichen Liturgie: durch puren Gesang, zeitlich eingebunden, räumlich unabhängig. ${ }^{150}$ Für dieses hierarchisch distinkte Modell von Assimilation und Partizipation wurde spätestens nach dem Trienter Konzil sogar eine gewisse Allgemeinverbindlichkeit reklamiert: »ex qua omnes exemplum sumere debent $\aleph^{151}$.

Eine alles übersteigende Funktion aber hatte die Aufführung von Motetten zwischen Offertorium und Communio: zur Elevation. Den liturgischen Büchern zufolge ist hier überhaupt kein Gesang vorgesehen. Entscheidend ist allein die Konsekration von Brot und Wein durch die Worte des zelebrierenden Priesters. Dabei handelte es sich nach zeitgenössisch geltender Sakramentaltheologie um den bedeutsamsten Akt der gesamten Messe. Nicht erst die konfessionellen Auseinandersetzungen des fortgeschrittenen 16. Jahrhunderts waren daher auf diesen Messteil fokussiert, sondern bereits die Auseinandersetzungen der Zeremonienmeister der Renaissance, die um die zu vollziehenden Zeremonien höchst unterschiedliche Auffassungen vertraten und darüber heftig stritten - im Unterschied zu den Reformatoren freilich unter Ausschluss der Öffentlichkeit. ${ }^{152}$ Die von den Sängern vorgetragenen Texte hingegen entstammten inoffiziellen Formen von Frömmigkeit, für die sich die Bezeichnung »Volksfrömmigkeit« - ungeachtet aller Probleme, die dieser Begriff aufwirft - durchgesetzt hat. ${ }^{153}$ Die spätestens mit dem Auf-

149 Siehe dazu J. Bölling, Das Papstzeremoniell der Renaissance (wie Anm. 3), S. 109-112 und ders., »Kinder, Chöre, Curricula. Zur Institutions- und Bildungsgeschichte von pueri cantores«, in: Rekrutierung musikalischer Eliten. Knabengesang im 15. und 16. Jahrhundert, hrsg. von Nicole Schwindt, Kassel 2013 (troja. Jahrbuch für Renaissancemusik 10/ 2011), S. 93-109: S. 97-99.

150 Vgl. oben Anm. 5.

151 Paridis Crassi Bononiensis olim apostolicarum cerimoniarum magistri et episcopi Pisaurensis De cerimoniis cardinalium et episcoporum in eorum dioecesibus libri duo, singulis etiam ecclesiarum canonicis valde necessarij, Rom 1564 (Nachdrucke: Rom 1580, Venedig 1582 und Rom 1587), Vorwort des herausgebenden Zeremonienmeister Franciscus Mucantius, ohne Foliierung. Siehe dazu J. Bölling, »Das Papstzeremoniell der Hochrenaissance« (wie Anm. 34), S. 289-291.

152 Vgl. dazu J. Bölling, Das Papstzeremoniell der Renaissance (wie Anm. 3), S. 94-101 und ders., »Reformation und Renaissance. Martin Luthers Romaufenthalt und die Reform des Papstzeremoniells«, in: Martin Luther in Rom: Kosmopolitisches Zentrum und seine Wabrnehmung. Tagung des Deutschen Historischen Instituts in Rom vom 16. bis 20. Februar 2011, hrsg. von Michael Matheus, Martin Wallraff und Arnold Nesselrath (im Druck).

153 Siehe dazu zuletzt etwa folgende von der Kurie herausgegebene Handreichung: Congregatio de Cultu Divino et Disciplina Sacramentorum. Direktorium über die Volksfrömmigkeit und die Liturgie. Grundsätze und Orientierungen, Vatikanstadt 2001 (Verlautbarungen des Apostolischen Stuhls, 
kommen der Elevation, der Erhebung der geweihten Hostie, entstandenen eucharistischen Gebete wurden bald nicht mehr von einzelnen Gläubigen privat und in aller Stille, sondern von den kirchenamtlich beauftragten Sängern korporativ und öffentlich vorgetragen - nunmehr mit musikalischen Mitteln, die alle bisherigen Anbetungsformen künstlerisch weit übertrafen. Eine Motette wie Josquins Tu solus qui facis mirabilia hinterlässt bereits als reines Musikstück einen besonderen Eindruck. ${ }^{154}$ Wie bewegend muss erst ihre Aufführung zur Elevation gewesen sein, belegbar etwa noch für das Jahr $1560 !^{155}$ Gleich das erste Wort, die Anrede $\gg \mathrm{Tu}$ «, »Du«, richtete sich aus der Sicht glaubender Partizipienten unmittelbar an den in der Hostie erhöhten Herrn. Doch auch für das rein musikalische Verhältnis der Gattungen von Motette und Messe ist die Elevation von besonderer Bedeutung. Bei der Abfolge von Introitus und Kyrie, Offertorium und Offertoriumsmotette, Agnus Dei, Communio und Motette zur Postcommunio mag Einstimmigkeit mit Mehrstimmigkeit unmittelbar verbunden worden sein, weil diese Gesänge die vom Zelebranten still vollzogenen Gebete so überdeckten, dass sie unmittelbar aufeinander folgten. ${ }^{156}$ Die Elevationsmotette hingegen legte sich als eine mehrstimmige Vertonung unmittelbar an das voraufgehende Sanctus und das anschließende Benedictus an oder ersetzte letzteres sogar. ${ }^{157}$ Dies hängt keineswegs damit zusammen, dass die Elevation bereits zwischen dem Gebet von Sanctus und Benedictus, also vor dem Canon missae, erfolgt wäre. ${ }^{158}$ Vielmehr betete der Zelebrant Sanctus und Benedictus während des Sanctus-Gesangs still und begann schon mit dem Canon missae, während der Chor noch immer beim Sanctus war. Die Sänger überdeckten so den ersten Teil des römischen Hochgebets bis zur Elevation vollständig mit dem Sanctus. Hatten sie diesen eher beendet als der Priester, hielten sie bis zur Elevation inne, war hingegen der Priester früher

160); Jörg Bölling, »Zwischen Liturgie und Volksfrömmigkeit. Wallfahrten im Spätmittelalter«, in: Objektive Feier und subjektiver Glaube? Beiträge zum Verbältnis von Liturgie und Spiritualität, hrsg. von Stefan Böntert, Regensburg 2011 (Studien zur Pastoralliturgie, 32), S. 35-62 .

154 Werken van Josquin des Prez, hrsg. von Albert Smijers, Bd. 2: Motetten. Teil 1, Amsterdam 1925, S. 56f.: Prima pars.

155 Jeremy Noble, »The function of Josquin's motets«, in: Tijdschrift van de Verenigung voor Nederlandse muziekgeschiedenis 35 (1985), S. 9-31: S. 12.

156 Vgl. J. Bölling, Das Papstzeremoniell der Renaissance (wie Anm. 3), S. 233-237 und S. 255259 sowie ders., Zeremoniell und Zeit (wie Anm. 7).

157 Vgl. J. Bölling, Musicae utilitas (wie Anm. 43), S. 260-264.

158 Diesen Lösungsvorschlag stellte J. Noble, The function of Josquin's motets (wie Anm. 155), S. 12, fragend zur Debatte, ohne in der nachfolgenden Diskussion eine Antwort zu erhalten (vgl. ebda., S. 23-31). 
fertig, wartete dieser das Ende des Sanctus-Gesangs ab. ${ }^{159}$ Nach den Einsetzungsworten wurden die Bibelworte zum Einzug Jesu in Jerusalem, »Benedictus qui venit in nomine Domini«, gesungen, wobei das Wort»venit« der bereits erfolgten Konsekration entsprechend als Perfekt statt als Präsenz gedeutet werden konnte: Soeben ist er gekommen, real präsent in der Hostie, die historische Epiphanie und eschatologische Parusie substantiell zusammenführend. Genau diesen, sonst in großer Stille beobachteten Moment markiert der Elevationsgesang. Die akustisch-musikalische Betonung war umso wichtiger, als die besonders ins Auge fallenden Kniebeugen vor und nach der Elevation erst im Ordo missae des Johannes Burckard von 1496 explizit gefordert wurden und sein Nachfolger Paris de Grassis diese gleich wieder abgeschafft wissen wollte. ${ }^{160}$ Die Form der Motette verlieh diesem Augenblick darüber hinaus dieselbe Höhe künstlerischer $» v i r t u s «{ }^{161}$ wie den Ordinariumsteilen der Messe. Daher wären zumindest Elevationsmotetten der Einteilung des Johannes Tinctoris zum Trotz aus rituell-zeremonieller Perspektive eher dem »cantus magnus« als dem »cantus mediocris« zuzuschreiben.

Die liturgische Ordnung scheint auch umgekehrt auf die Repertoirebildung zurückgewirkt zu haben. Im bereits erwähnten Chorbuch CS 42 sind die Motetten, darunter Compères besprochene Werke Sola caret monstris und Ad honorem tuum, Christe, sogar so geordnet worden, dass die Forschung hierfür die »Konstituierung einer quasi liturgischen Ordnung mehrstimmiger Stücke ${ }^{162}$ reklamiert hat. Auch wenn dieses Chorbuch seine endgültige heutige Gestalt erst zu einem späteren Zeitpunkt erhalten haben mag, ist eine dauerhafte Tendenz der Verstetigung eines polyphonen liturgischen Repertoires unübersehbar. ${ }^{163}$ Es wäre jedoch verfehlt, die Wechselwirkung zwischen Musik und Liturgie auf diese Entwicklung zu beschränken. Die zahlreichen zu okkasionellen Anlässen denkbaren Motetten waren weiterhin im höfischen wie kirchlichen Kontext aufführbar. Dies betrifft vor allem Kompositionen mit Kombinationen von Textkompilationen und Paraphra-

159 Vgl. dazu zuletzt J. Bölling, Zeremoniell und Zeit (wie Anm. 7), S. 149-176.

160 Siehe oben Anm. 48 und J. Bölling, Das Papstzeremoniell der Renaissance (wie Anm. 3), S. 99.

161 Zum Begriff der »virtus« zur Bezeichnung professionalisierter Fähigkeiten in Kunst und Musik siehe J. Bölling, Das Papstzeremoniell (wie Anm. 3), S. 194. Zur päpstlichen Virtus siehe oben Anm. 148.

162 H. Hucke, Die Musik in der Sixtinischen Kapelle (wie Anm. 80), S. 163.

163 Zum Chorbuch selbst und dessen möglicherweise erst später angelegter heutiger Anordnung der Motetten s. R. Sherr, The Papal Chapel (wie Anm. 25), S. 227-246 sowie oben Anm. 99, zur Entwicklung der liturgischen Motettenaufführung in den nachfolgenden Jahrhunderten H. Möller, Motetten nach dem Offertorium (wie Anm. 134). 
sen. Die besonders eindringliche, jedoch kaum untersuchte Motette Omnis pulchritudo von Andrea de Silva etwa, um nur ein Beispiel zu nennen, stellt keine reine Vertonung eines einzigen liturgischen Textes dar, sondern die Kombination verschiedener Textabschnitte unterschiedlicher Gottesdienste des Himmelfahrtstages. ${ }^{164}$ In weitaus größerem Maße als bei den streng liturgischen Motetten vermochte sich hier die korporative Frömmigkeitspraxis der Sänger Gehör zu verschaffen. Deshalb sind neben den einschlägigen gregorianischen Vorlagen in päpstlichem Umfeld auch Quellen aus den Herkunftsländern der Sänger zu berücksichtigen.

\section{Fazit}

Die überlieferten, gänzlich geistlichen Motetten des Papsthofes der Renaissance waren hinsichtlich ihrer Texte wie auch ihrer musikalischen Faktur nicht nur von der kirchlichen Liturgie, sondern auch von der Frömmigkeitspraxis der ausführenden Korporation bestimmt. Da sich die gesamte Liturgie- und Zeremonialordnung der Kurie an der päpstlichen Kapelle orientierte, kam deren Sängerkollegium eine mustergültig tonangebende Bedeutung zu. Für die römische Kirche bildete die päpstliche Kapelle eine herausragende Korporation, ebenso wie innerhalb dieser das »collegium cantorum «, dessen einzelne Mitglieder wiederum bestimmte Ämter versahen, persönliche Fähigkeiten einbrachten und ihrerseits größere Verbünde repräsentierten - einzelne Hofkapellen oder Kompositionsschulen, aber auch ganze »nationes«. Darüber hinaus waren viele von ihnen Mitglieder anderer Korporationen wie etwa Bruderschaften. Hinsichtlich der Schriftlichkeit der Motetten ist zwischen den musikalischen Kompositionen der Sänger selbst und den für ihre Aufführung bedeutsamen literarischen Texten der Zeremonienmeister zu unterscheiden. Dazwischen bestehen zahlreiche Analogien, jedoch keine Interdependenzen. Drei beispielhaft ausgewählte Motetten verdeutlichen drei verschiedene Überlieferungszusammenhänge von Schriftlichkeit: erstens zeremonielle Bezeugung ohne Noten, zweitens Noten mit korrumpiert überliefertem Text ohne zeremonielle Bezeugung und drittens Noten mit außermusikalischen Angaben zu analogen liturgischen oder zeremoniellen Fällen. Im ersten Fall stellt sich die Frage nach einer möglichen musikalischen Faktur aufgrund der literarischen Form, wobei letztere sicherlich von Anfang an im Vordergrund stand. Im zweiten Fall deutet der zu rekonstruierende Text auf die liturgische und zeremonielle Verwendung, so dass dieser auf kirchliche und korporative sowie

164 Vergleichbare Fälle untersucht R. Köhler, Die Cappella Sistina (wie Anm. 12), S. 158-162. 
geistliche und weltliche Aspekte zu untersuchen und von dort aus in Liturgie und Zeremoniell zu verorten ist. Im dritten und letzten Fall führt der Analogieschluss zum Ergebnis - mit Blick auf vergleichbare Anlässe in denselben Quellengattungen, aber auch im wechselseitigen Vergleich zwischen biblischliturgischen und literarisch-musikalischen Texten und deren Vertonungen. Diese drei Verfahren lassen sich auch auf die Frage nach der Aufführungspraxis der Motetten selbst und deren liturgisch-zeremoniellen Kontext anwenden. Dabei sind drei verschiedene Arten von Anlässen zu unterscheiden: ephemere, okkasionelle und reguläre. Ephemere Ereignisse bilden traditionell zentrale Ansatzpunkte der Forschung, lassen sich aber nicht immer einwandfrei ermitteln. Okkasionelle Anlässe sind häufig denkbar, lassen aber den Zeremonienbüchern nach eher eine Tendenz zur Einstimmigkeit erkennen, die allenfalls ereignisbedingt durch einzelne dann ephemer erklingende Motetten hat ersetzt oder ergänzt werden können. Die reichsten Aufführungsmöglichkeiten bot, zumindest hinsichtlich der erhaltenen Quellen, die reguläre Liturgie. Die hohe Anzahl an Motettenkompositionen im Fondo Cappella Sistina und damit im Repertoire der päpstlichen Kapelle ist insofern nicht weiter verwunderlich, als regelmäßig aufgeführte Motetten auch eine wesentlich größere Überlieferungschance hatten als einmalig oder selten erklingende. Andererseits spricht aber die regelmäßige Aufführung für deren besondere Wertschätzung, und wo bei herausragenden Ereignissen keine verschriftlichte Motette vorliegt, ist zumindest festzustellen, dass die langfristige kommemorative Absicht nicht in der gleichen Weise ausgeprägt gewesen sein dürfte. Darüber hinaus vermochte sogar die reguläre Liturgie einzelne ephemere Motetten zu integrieren. Deren personen- und nationenbezogene Tendenz überlebte dann das ursprüngliche Ereignis. Innerhalb der Liturgie spielte die Messe eine entscheidende Rolle, und zwar bei jenen Abschnitten, die nicht vom Ordinarium missae ausgefüllt waren und doch aus Gründen der zeitlichen Organisation der Zeremonien eine akustische Überbrückung und eine künstlerische Hebung der gottesdienstlichen Feierlichkeit erheischten: Offertorium, Elevation und Communio. Die Sänger halfen hier nicht nur bei der zeitlichen Strukturierung der Zeremonien, sondern kommentierten die allgemein gültige kirchliche Liturgie und brachten so ihre eigene korporative Frömmigkeitspraxis performativ zu Gehör. 